\title{
Chronic hM4Di-DREADD-Mediated Chemogenetic Inhibition of Forebrain Excitatory Neurons in Postnatal or Juvenile Life Does Not Alter Adult Mood-Related Behavior
}

\author{
Praachi Tiwari, Darshana Kapri, ${ }^{-A m a r t y a ~ P r a d h a n, ~ A n g a r i k a ~ B a l a k r i s h n a n, ~ P r a t i k ~ R . ~ C h a u d h a r i, ~ a n d ~}$ \\ DVidita A. Vaidya
}

https://doi.org/10.1523/ENEURO.0381-21.2021

Department of Biological Sciences, Tata Institute of Fundamental Research, Mumbai 400005, India

\begin{abstract}
G-protein-coupled receptors (GPCRs) coupled to $G_{i}$ signaling, in particular downstream of monoaminergic neurotransmission, are posited to play a key role during developmental epochs (postnatal and juvenile) in shaping the emergence of adult anxiodepressive behaviors and sensorimotor gating. To address the role of $G_{i}$ signaling in these developmental windows, we used a CaMKII $\alpha$-tTA::TRE hM4Di bigenic mouse line to express the hM4Di-DREADD (designer receptor exclusively activated by designer drugs) in forebrain excitatory neurons and enhanced $G_{i}$ signaling via chronic administration of the DREADD agonist, clozapine- $N$-oxide (CNO) in the postnatal window (postnatal days 2-14) or the juvenile window (postnatal days 28-40). We confirmed that the expression of the HA-tagged hM4Di-DREADD was restricted to CaMKIl $\alpha$-positive neurons in the forebrain, and that the administration of $\mathrm{CNO}$ in postnatal or juvenile windows evoked inhibition in forebrain circuits of the hippocampus and cortex, as indicated by a decline in expression of the neuronal activity marker c-Fos. hM4Di-DREADD-mediated inhibition of CaMKII $\alpha$-positive forebrain excitatory neurons in postnatal or juvenile life did not impact the weight profile of mouse pups, and also did not influence the normal ontogeny of sensory reflexes. Further, postnatal or juvenile hM4Di-DREADD-mediated inhibition of CaMKII $\alpha$-positive forebrain excitatory neurons did not alter anxiety- or despair-like behaviors in adulthood and did not impact sensorimotor gating. Collectively, these results indicate that chemogenetic induction of $\mathrm{G}_{\mathrm{i}}$ signaling in $\mathrm{CaMKII} \alpha$-positive forebrain excitatory neurons in postnatal and juvenile temporal windows does not appear to impinge on the programming of anxiodepressive behaviors in adulthood.
\end{abstract}

Key words: anxiety; depression; DREADD; early life; $\mathrm{G}_{\mathrm{i}}$ signaling; schizophrenia

\section{Significance Statement}

The experience of early adversity can program persistent alterations in mood-states. It has been suggested that a perturbation of signaling pathways within forebrain neurocircuits, in particular a disruption of the balance between $G_{q}$ and $G_{i}$ signaling in forebrain excitatory neurons during critical developmental epochs may program the dysregulation of anxiodepressive behaviors. Prior evidence indicates that increased $\mathrm{G}_{\mathrm{q}}$ signaling-mediated activation of forebrain excitatory neurons in postnatal life can enhance adult anxiodepressive behaviors. Here, we have addressed whether $\mathrm{G}_{i}$ signaling-mediated inhibition of forebrain excitatory neurons in the postnatal and juvenile windows of life can influence adult anxiodepressive behaviors. Our findings indicate that chronic chemogenetic inhibition of forebrain excitatory neurons via $\mathrm{G}_{\mathrm{i}}$-mediated signaling during critical developmental time windows does not impact mood-related behavior. 


\section{Introduction}

Experiences during early developmental windows play a crucial role in the fine-tuning and shaping of an individual's behavioral and functional responses in adulthood (Gross and Hen, 2004; Hensch, 2005; Ansorge et al., 2007; Bale et al., 2010; Di Segni et al., 2018). While exposure to early stress and trauma is associated with persistent increases in anxiety- and despair-like behavior in preclinical studies (Chen and Baram, 2016; De Melo et al., 2018; Targum and Nemeroff, 2019; Wang et al., 2020), enriched environment exposure (Kempermann et al., 1997; Francis et al., 2002; Cymerblit-Sabba et al., 2013; Ravenelle et al., 2014; Sparling et al., 2018) and high maternal care during these early temporal windows is associated with enhanced stress coping and resilient behavioral responses (Bredy et al., 2003; Champagne et al., 2008; Bagot et al., 2009). The neurotransmitter, 5-hydroxytryptamine (serotonin; 5-HT), and signaling via the $\mathrm{G}_{\mathrm{i}}$-coupled 5- $\mathrm{HT}_{1 \mathrm{~A}}$ and $\mathrm{G}_{\mathrm{q}}$-coupled 5- $\mathrm{HT}_{2 \mathrm{~A}}$ receptors, has been implicated in playing an important role in shaping the development of mood-related behavior (Gordon and Hen, 2004; Altieri et al., 2015; Tiwari et al., 2021). Elevation of 5-HT levels during postnatal life, either via pharmacological blockade or genetic loss of function of the $5-\mathrm{HT}$ transporter, is associated with enhanced anxiety- and despairlike behavior that persists across the life span (Ansorge et al., 2004, 2008; Sarkar et al., 2014). Loss of function of the $\mathrm{G}_{\mathrm{q}}$-coupled $5-\mathrm{HT}_{2 \mathrm{~A}}$ receptor, in particular in the forebrain, is associated with reduced anxiety-like behavior (Weisstaub, 2006), whereas loss of function of the $\mathrm{G}_{\mathrm{i}}$-coupled 5- $\mathrm{HT}_{1 \mathrm{~A}}$ receptor during postnatal life, in both forebrain and raphe neurocircuits, has been linked to increased anxiety-like behavior (Gross et al., 2002; Vinkers et al., 2010; Richardson-Jones et al., 2010, 2011; Mineur et al., 2015). Furthermore, pharmacological blockade of the $\mathrm{G}_{\mathrm{i}}$-coupled $5-\mathrm{HT}_{1 \mathrm{~A}}$ receptor during postnatal life is associated with the emergence of increased anxiety in adulthood (Vinkers et al., 2010; Garcia-Garcia et al., 2014; Sarkar et al., 2014), whereas pharmacological stimulation of the $\mathrm{G}_{\mathrm{q}}$-coupled 5- $\mathrm{HT}_{2 \mathrm{~A}}$

Received September 19, 2021; accepted December 25, 2021; First published February 3, 2022

The authors declare no competing financial interests.

Author contributions: P.T. and V.A.V. designed research; P.T., D.K., A.P., A.B., P.R.C., and V.A.V. performed research; P.T., D.K., and A.B. contributed unpublished reagents/analytic tools; P.T., D.K., A.P., and P.R.C. analyzed data; P.T. and V.A.V. wrote the paper.

The study was supported by project RTI4003 from the Department of Atomic Energy to Tata Institute of Fundamental Research, and by the Sree Ramakrishna Paramahamsa Research Grant (2020) from the Sree Padmavathi Venkateswara Foundation (SreePVF), Vijayawada, Andhra Pradesh.

Acknowledgements: We thank Dr. Shital Suryavanshi, Urvi Mishra, and the animal house staff at the Tata Institute of Fundamental Research, Mumbai, for technical assistance.

Correspondence should be addressed to Vidita A. Vaidya at vvaidya@ tifr.res.in.

https://doi.org/10.1523/ENEURO.0381-21.2021

Copyright @ 2022 Tiwari et al.

This is an open-access article distributed under the terms of the Creative Commons Attribution 4.0 International license, which permits unrestricted use, distribution and reproduction in any medium provided that the original work is properly attributed. receptors (Sarkar et al., 2014) or enhanced $G_{q}$ signaling driven via chemogenetic activation of excitatory forebrain neurons during postnatal window programs increased anxiety- and despair-like behavior in adulthood (Pati et al., 2020).

It has been hypothesized that early stress may shift the balance toward enhanced excitatory $\mathrm{G}_{\mathrm{q}}$-coupled signaling accompanied by a decline in inhibitory $\mathrm{G}_{\mathrm{i}}$-coupled signaling in forebrain neurocircuits, which could contribute to the programming of perturbed anxiety- and despair-like behaviors (Sumner et al., 2008; Lambe et al., 2011; Tiwari et al., 2021). Chemogenetic studies indicate that enhanced $G_{q}$ signaling in forebrain excitatory neurons during postnatal life programs long-lasting increases in anxiety- and despair-like behavior along with disrupted sensorimotor gating (Pati et al., 2020). Several preclinical studies suggest that a loss or reduction in signaling via the $\mathrm{G}_{\mathrm{i}}$-coupled 5$\mathrm{HT}_{1 \mathrm{~A}}$ receptor during the postnatal temporal window enhances anxiodepressive behaviors in adulthood (Ramboz et al., 1998; Gross et al., 2000, 2002; Vinkers et al., 2010; Richardson-Jones et al., 2010, 2011). However, a recent study indicates that enhanced $G_{i}$ signaling driven chemogenetically in prefrontal cortical neurons during postnatal life results in enhanced adult anxiety- and despair-like behavior, phenocopying the effects of early stress (Teissier et al., 2020). Clinical evidence based on studies of 5- $\mathrm{HT}_{1 \mathrm{~A}}$ receptor binding suggests that $\mathrm{G}_{\mathrm{i}}$-coupled receptors may be associated with resilience to anxiety (Savitz et al., 2009; Armbruster et al., 2011; Albert et al., 2019). Collectively, these reports provide impetus for experiments to test whether perturbation of $G_{i}$ signaling in forebrain excitatory neurons during early developmental windows can alter the programming of mood-related behaviors.

Here, we directly addressed the influence of increased $\mathrm{G}_{\mathrm{i}}$-mediated signaling in forebrain excitatory neurons in postnatal and juvenile life in the shaping of anxiety- and despair-like behavior, as well as sensorimotor gating responses, in adulthood. We used the $\mathrm{G}_{\mathrm{i}}$-coupled inhibitory (hM4Di) designer receptors exclusively activated by designer drugs (DREADD), which were expressed in CaMKIl $\alpha$-positive forebrain excitatory neurons via a bigenic mouse line (CaMKIl $\alpha$-tTA::TRE hM4Di; Alexander et al., 2009) and used the DREADD ligand clozapine- $N$ oxide (CNO; $5 \mathrm{mg} / \mathrm{kg}$; Roth, 2016) to activate $\mathrm{G}_{i}$ signaling during the postnatal window [postnatal day 2 (P2) to P14] and juvenile window (P28 to P40) followed by behavioral analysis in adulthood. We show that hM4Di-DREADDmediated inhibition of CaMKII $\alpha$-positive forebrain excitatory neurons in either the postnatal or juvenile temporal windows does not influence anxiety- and despair-like behavior or sensorimotor gating in adulthood.

\section{Materials and Methods}

\section{Animals}

Bigenic CaMKIla-tTA::TRE-hM4Di mice were used for all experiments. The CaMKIla-tTA transgenic mouse line (Mayford et al., 1996) was a gift from Christopher Pittenger (Department of Psychiatry, Yale School of Medicine, New Haven, CT). The TRE-hM4Di mouse line 
was purchased from The Jackson Laboratory [B6.CgTg(tetO-CHRM4*)2Blr/J; catalog \#024114, The Jackson Laboratory]. Bigenic animals were generated for the experiments by mating CaMKIla-tTA::TRE-hM4Di males to CaMKIla-tTA::TRE-hM4Di females. The genotypes were confirmed by PCR-based analysis. All dams were individually housed in separate cages, and litter size was restricted to six to eight pups per litter. All animals were bred and maintained in the Tata Institute of Fundamental Research (TIFR; Mumbai, India) animal house facility on a $12 \mathrm{~h}$ light/dark cycle from 7:00 A.M. to $7 \mathrm{pm}$, with ad libitum access to food and water. Experimental procedures were conducted as per the guidelines of the Committee for the Purpose of Control and Supervision of Experiments on Animals, Government of India, and were approved by the TIFR animal ethics committee. Care was taken across all experiments to minimize any pain or suffering and to restrict the number of animals used.

\section{Drug treatment paradigms}

For postnatal drug treatments, bigenic CaMKII $\alpha$-tTA:: TRE-hM4Di mouse pups were orally administered either CNO (catalog \#4963, Tocris Bioscience; $5 \mathrm{mg} / \mathrm{kg}$ in $5 \%$ sucrose solution containing $1 \%$ DMSO) or vehicle ( $5 \%$ sucrose solution containing $1 \% \mathrm{DMSO}$ ) for $13 \mathrm{~d}$, commencing from P2 to P14. Postweaning (P24 to P27), animals were group housed for 3 months before assessment on behavioral assays. For juvenile drug treatments, bigenic CaMKII $\alpha$-tTA::TRE-hM4Di mouse pups were weaned between P24 and P27, group housed, and randomly assigned to either the vehicle or CNO treatment groups. Juvenile bigenic CaMKII $\alpha$-tTA::TRE-hM4Di mice received either CNO $(5 \mathrm{mg} / \mathrm{kg}$ in $5 \%$ sucrose solution containing $1 \%$ DMSO) or vehicle (5\% sucrose solution containing $1 \% \mathrm{DMSO}$ ) for $13 \mathrm{~d}$ from P28 to P40. All animals were left undisturbed from P41 for 2 months before subjecting them to behavioral testing. To assess whether postnatal CNO (PNCNO) or juvenile CNO (JCNO) treatment influenced the weight of pups, we conducted an extensive weight profiling across the duration of the PNCNO and JCNO treatment paradigms. We chose the treatment time windows to reflect a postnatal window in which early stress paradigms are performed, and a juvenile window postweaning.

\section{Western blotting}

To assess HA-tagged hM4Di-DREADD expression in the hippocampus and cortex of CaMKIl $\alpha$-tTA::TREhM4Di bigenic mice at P7 and P35, we conducted Western blotting analysis for the HA antigen. To determine the influence of CNO-mediated activation of the hM4Di-DREADD on neuronal activity marker expression (c-Fos), we administered a single dose of CNO (5 mg/ $\mathrm{kg}$ ) or vehicle to CaMKII $\alpha$-tTA::TRE-hM4Di bigenic mouse pups at P7 and to the juvenile cohort at P35, and killed them 30 min postadministration. Hippocampi and cortex tissue were dissected and homogenized in radioimmunoprecipitation assay buffer (50 nM Tris-Cl, $\mathrm{pH}$ 8.0, 5 mм EDTA, 1\% NP-40, $150 \mathrm{~mm} \mathrm{NaCl}$ ) using a dounce homogenizer. Protein concentration was estimated with the QuantiPro BCA Assay Kit (Sigma-Aldrich), and lysates were resolved on a $10 \%$ SDS polyacrylamide gel before transfer onto polyvinylidene fluoride membranes. Blots were subjected to blocking in 5\% milk in TBST and incubated overnight with the following respective primary antibodies: rabbit anti-HA (1:1500; catalog \#H6908, Sigma-Aldrich); rabbit anti-c-Fos (1:1000; catalog \#2250, Cell Signaling Technology); and rabbit anti- $\beta$-actin (1:10,000; catalog \#AC026, ABclonal Technology). Blots were exposed to HRPconjugated goat anti-rabbit secondary antibody (1:6000; catalog \#AS014, ABclonal Technology) for $1 \mathrm{~h}$ with signal visualized on an Imager 600 (GE Healthcare) using a Western blotting detection kit (WesternBright ECL, Advansta). Densitometric quantitative analysis was performed using ImageJ software.

\section{Immunofluorescence analysis}

Coronal brain sections $(40 \mu \mathrm{m})$ were generated on a vibratome (Leica) from adult CaMKIl $\alpha$-tTA::TRE-hM4Di bigenic mice killed by transcardial perfusion with $4 \%$ paraformaldehyde. Sections were permeabilized and blocked in PBS with $0.3 \%$ Triton X-100 (PBSTx) containing 10\% horse serum (catalog \#26-050-088, Thermo Fisher Scientific) for $2 \mathrm{~h}$ at room temperature. The sections were then incubated with primary antibody for double-labeled immunofluorescence experiments to examine the colocalization of the HA-tagged hM4Di-DREADD with markers for excitatory and inhibitory neurons, and glial cells in the hippocampus and neocortex. The following antibody cocktails were used: rat anti-HA (1:200; catalog \#10145700, Roche Diagnostics) with rabbit anti-CaMKIl $\alpha$ (1:200; catalog \#sc-12 886-R, Santa Cruz Biotechnology), mouse anti-parvalbumin (PV; 1:500; catalog \#P3088, Sigma-Aldrich), or rabbit anti-glial fibrillary acidic protein (GFAP; 1:500; catalog \#AB5804, Chemicon) for $4 \mathrm{~d}$ at $4{ }^{\circ} \mathrm{C}$. This was followed by the washing of sections with $0.3 \%$ PBSTx three times for $15 \mathrm{~min}$ each. The sections were then incubated with the following cocktails of secondary antibodies: goat anti-rat IgG conjugated to Alexa Fluor 488 (1:500; catalog \#A-21212, Thermo Fisher Scientific) and goat antirabbit IgG conjugated to Alexa Fluor 568 (1:500; catalog \#A-11011, Thermo Fisher Scientific), or goat anti-rat IgG conjugated to Alexa Fluor 488 (1:500; catalog \#A-21212, Thermo Fisher Scientific) and donkey anti-mouse IgG conjugated to Alexa Fluor 555 (1:500; catalog \#A-31570, Thermo Fisher Scientific) for $2 \mathrm{~h}$ at room temperature. After sequential washing with $0.3 \%$ PBSTx, sections were mounted on slides using Vectashield Antifade Mounting Medium with DAPI (catalog $\# \mathrm{H}-1200$, Vector Laboratories) and images were visualized on a confocal microscope (model FV1200, Olympus).

\section{Behavioral assays}

Reflex behaviors for neonates were analyzed on $\mathrm{CaMKIl} \alpha$ tTA::TRE-hM4Di bigenic mouse pups commencing on P9 till $\mathrm{P} 12$, with air righting, surface righting, and negative geotaxis determined.

\section{Air righting}

Animals were allowed to fall 10 times from a height of $25 \mathrm{~cm}$, facing upside down. The number of correct 
landings, as observed by falling on all four paws, was determined.

\section{Negative geotaxis}

Animals were placed on an inclined plank $\left(30^{\circ}\right)$, facing downward. The length of time taken by the animal to turn $\left(180^{\circ}\right)$ and face upward was noted.

\section{Surface righting}

The time for the pup to attain a standing position with all four paws was noted when placed upside down in the home cage.

In adulthood, CaMKII $\alpha$-tTA::TRE-hM4Di bigenic mice were subjected to behavioral assays to assess anxietylike behavior [open field test (OFT); elevated plus maze (EPM) test; light-dark avoidance test (LD box)] despairlike behavior [tail suspension test (TST) and forced swim test (FST)], and sensorimotor gating behavior, which was assessed via the prepulse inhibition (PPI) test. All anxietylike behavioral assays were recorded and tracked using an overhead camera at 25 frames/s. All despair-like behaviors were recorded using a side-mounted webcam (Logitech). Behavior tracking was performed using the automated platform Ethovision XT 11.

\section{Open field test}

Mice were released into one corner (chosen at random) of the open field arena $(40 \times 40 \times 40 \mathrm{~cm})$, and were allowed to explore for $10 \mathrm{~min}$. The total distance moved in the arena, the percentage of time spent and the percentage of distance in the center, and the number of entries to the center were determined.

\section{Elevated plus maze}

Animals were introduced to the elevated plus maze for $10 \mathrm{~min}$ and were placed in the center of the plus maze facing the open arms. The elevated plus maze was built such that the two arms both open and closed $(30 \times 5 \mathrm{~cm}$ each) were elevated $50 \mathrm{~cm}$ above the ground. The walls of the closed arms were $15 \mathrm{~cm}$ high. The total distance moved in the maze, the percentage of time spent, the percentage of distance, and the number of entries in the open and closed arms were determined.

\section{Light-dark avoidance test}

The LD box was made of two joint chambers: the light chamber $(25 \times 25 \mathrm{~cm})$ and the dark chamber $(15 \times$ $25 \mathrm{~cm})$. The two areas were connected by an opening (10 $\times 10 \mathrm{~cm}$ ). Mice were released into the arena facing the light chamber at the cusp of the lit and dark arenas for a duration of $10 \mathrm{~min}$. The number of entries and the percentage of time spent in the light arena were assessed.

\section{Tail suspension test}

Animals were suspended by their tail for $6 \mathrm{~min}$ at a height of $50 \mathrm{~cm}$ above the ground, and the total immobility time and number of immobility events were assessed for a duration of $5 \mathrm{~min}$, excluding the first minute of the test.

\section{Forced swim test}

Animals were allowed to swim for 6 min in a transparent cylinder $50 \mathrm{~cm}$ in height with a $14 \mathrm{~cm}$ inner diameter that was filled with water $\left(25^{\circ} \mathrm{C}\right)$ up to a height of $30 \mathrm{~cm}$. The total immobility time and the number of immobility events were determined for a duration of 5 min excluding the first minute of the test.

\section{Prepulse inhibition test}

Animals were assayed for perturbation of sensorimotor gating on the prepulse inhibition test performed using a startle and fear conditioning apparatus (Panlab). CaMKII $\alpha$-tTA::TRE-hM4Di bigenic mice were allowed to habituate to the restrainer and testing apparatus for 15 min daily across $4 \mathrm{~d}$, followed by a 15 min habituation per day for $4 \mathrm{~d}$ with an exposure to $65 \mathrm{~dB}$ background white noise. On the test day, following exposure of the animals to $65 \mathrm{~dB}$ background white noise for $5 \mathrm{~min}, 10$ tone pulses $(120 \mathrm{~dB}, 1 \mathrm{~s})$ were presented to the mice to measure basal startle response (first block). The mice were then randomly presented with either only tone $(120 \mathrm{~dB}, 1$ $\mathrm{s}, 10 \times)$ or a $100 \mathrm{~ms}$ prepulse that was $+4 \mathrm{~dB}(69 \mathrm{~dB})$, $+8 \mathrm{~dB}(73 \mathrm{~dB})$, or $+16 \mathrm{~dB}(81 \mathrm{~dB})$ higher than the background noise, five times each, which coterminated with a $1 \mathrm{~s}, 120 \mathrm{~dB}$ tone. The percentage of PPI was calculated using the following formula: percentage PPI $=100 \times($ average startle response with only tone - average startle response with the prepulse)/average startle response with only tone.

\section{Statistical analysis}

The Kolmogorov-Smirnov test was used to confirm the normality of distribution. All experiments that had two treatment groups were subjected to a two-tailed, unpaired Student's $t$ test using GraphPad Prism (GraphPad Software). A Welch correction was applied when a significant difference in the variance between groups was observed. Experiments with four treatment groups were subjected to a two-way ANOVA with PNCNO and sex as the two variables. The Tukey's post hoc comparison tests were performed only when a significant two-way ANOVA interaction of PNCNO $\times$ sex interaction was observed. Data are expressed as the mean \pm SEM, and statistical significance was set at $p<0.05$.

\section{Results}

\section{Selective expression of hM4Di-DREADD in CaMKIl $\alpha$ - positive forebrain excitatory neurons in CaMKII $\alpha$-tTA:: TRE-hM4Di bigenic mice}

To address the behavioral consequences of hM4DiDREADD-mediated inhibition of forebrain excitatory neurons in postnatal and juvenile windows of life, CaMKIl $\alpha$-tTA::TREhM4Di bigenic mice were generated. The expression of the HA-tagged hM4Di-DREADD was characterized in the hippocampus and cortex, wherein the CaMKII $\alpha$-tTA driver would result in expression in forebrain excitatory neurons (Mayford et al., 1996; Wang et al., 2013), as well as within brain regions such as the periaqueductal gray (PAG) and pallidum, which are known to lack an expression of $\mathrm{CaMKIl} \alpha$-positive neurons. The presence of the HAtagged hM4Di-DREADD was confirmed in CaMKII $\alpha$-positive neurons in both the hippocampus (Fig. 1A) and the cortex (Fig. 1D) of adult CaMKII $\alpha$-tTA::TRE-hM4Di bigenic 

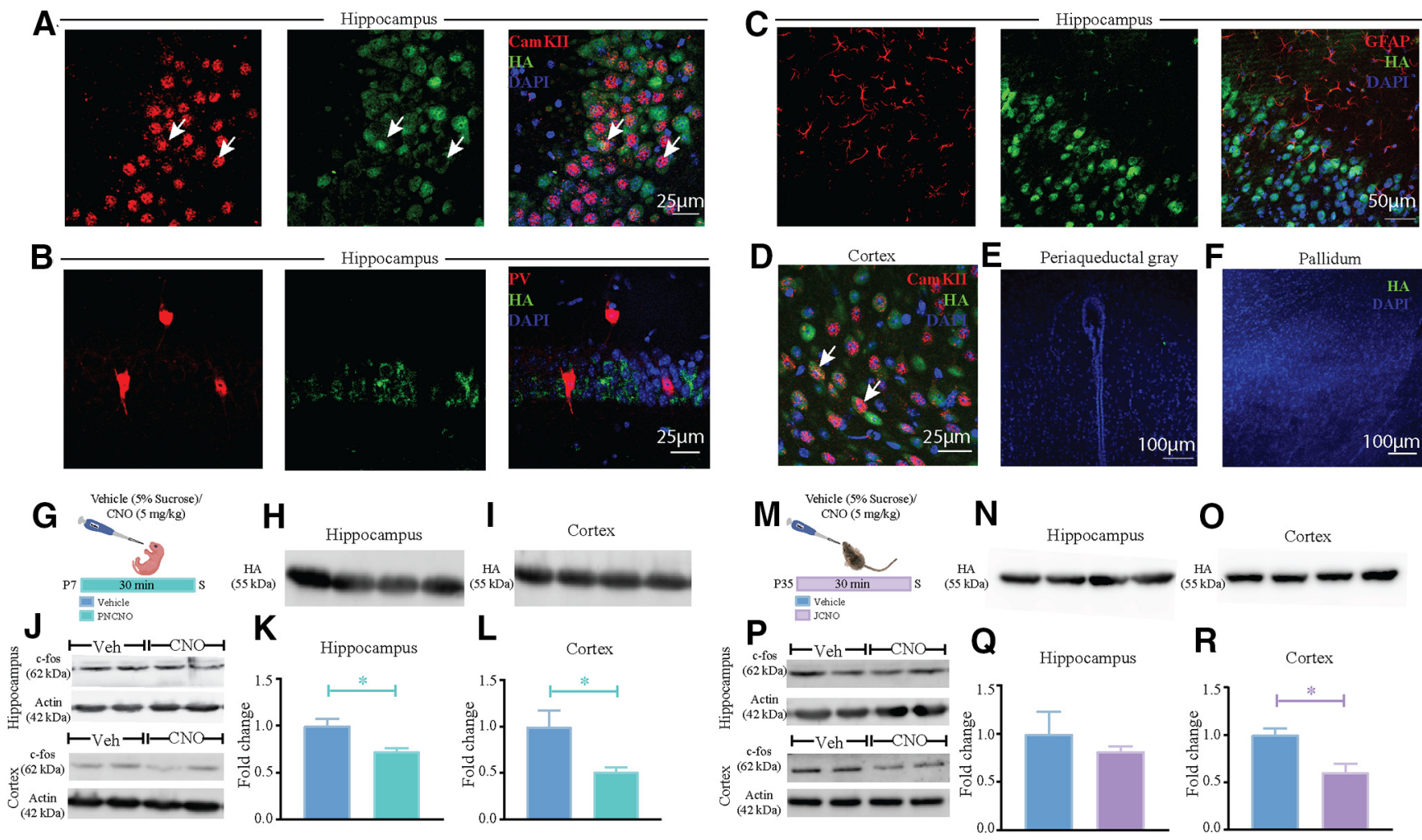

$\mathbf{R}$

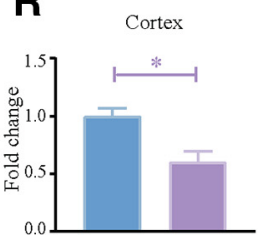

Figure 1. Selective expression of hM4Di-DREADD in CaMKIl $\alpha$-positive forebrain excitatory neurons in CaMKIl $\alpha$-tTA::TRE-hM4Di bigenic mice. $\boldsymbol{A}$, Shown are representative confocal images indicating expression of the HA-tagged hM4Di-DREADD in the hippocampus as identified by HA/CaMKIl $\alpha$ double immunofluorescence. $\boldsymbol{B}, \boldsymbol{C}, \mathrm{HA}$-tagged hM4Di-DREADD expression was not observed in either PV-positive inhibitory interneurons $(\boldsymbol{B})$ or GFAP-positive astrocytes $(\boldsymbol{C})$. $\boldsymbol{D}$, HA-tagged hM4Di-DREADD in the cortex was also observed in the CaMKII $\alpha$-positive neurons as identified with HA/CaMKII $\alpha$ double immunofluorescence. $\boldsymbol{E}, \boldsymbol{F}$, Immunofluorescence experiments indicate the absence of expression of HA-tagged hM4Di-DREADD in subcortical brain regions, namely the periaqueductal gray $(\boldsymbol{E})$ and pallidum $(\boldsymbol{F})$. G. Shown is a schematic of the experimental paradigm for harvesting cortex and hippocampus at P7 for Western blotting analysis. $\boldsymbol{H}, \boldsymbol{I}, \mathrm{HA}$ expression was clearly noted in the cortex $(\boldsymbol{H})$ as well as the hippocampus $(\boldsymbol{I})$ in Western blots from CaMKII $\alpha$-tTA::TRE-hM4Di bigenic pups (P7). J, Shown are representative Western blots for c-Fos along with their respective actin loading controls at P7 half an hour after vehicle (Veh) or CNO treatment for cortex (top panel) and hippocampus (bottom panel). $\boldsymbol{K}, \boldsymbol{L}$, Quantitative densitometry indicated a significant reduction in c-Fos protein levels in the cortex $(\boldsymbol{K})$ as well as the hippocampus $(\boldsymbol{L})$ of PNCNO-treated bigenic pups at P7 compared with their vehicle-treated controls. $\boldsymbol{M}$, Shown is a schematic of the experimental paradigm for harvesting cortex and hippocampus at P35 in the juvenile window for Western blotting analysis. $\boldsymbol{N}$, $\boldsymbol{O}, \mathrm{HA}$ expression was noted in the cortex $(\boldsymbol{N})$ as well as the hippocampus $(\boldsymbol{O})$ of CaMKIl $\alpha$-tTA::TRE-hM4Di bigenic juvenile mice (P35). $\boldsymbol{P}$, Shown are representative Western blots for c-Fos along with their respective actin loading controls at P35 half an hour after vehicle (Veh) or CNO treatment for cortex (top panel) and hippocampus (bottom panel). $\boldsymbol{Q}, \boldsymbol{R}$, Quantitative densitometry indicated a significant reduction in c-Fos protein levels in the cortex $(\boldsymbol{Q})$ but not in the hippocampus $(\boldsymbol{R})$ of JCNO-treated bigenic mice at P35 compared with their vehicle-treated controls. All immunofluorescence experiments and Western blotting experiments were performed on $n=3-5 /$ group. Results are expressed as the mean \pm SEM. ${ }^{*} p<0.05$, compared with vehicle-treated controls using the two-tailed, unpaired Student's $t$ test.

mice. The HA-tagged hM4Di-DREADD was not present on the inhibitory PV-positive neurons (Fig. 1B), as well as in GFAP-immunopositive astrocytes (Fig. 1C) in the hippocampus. We also confirmed the absence of the HA-tagged hM4Di-DREADD in select brain regions that lack CaMKII $\alpha$-positive neurons, namely the PAG (Fig. 1E) and pallidum (Fig. 1F).

We next examined the presence of the HA-tagged $\mathrm{hM}$ 4Di-DREADD in the hippocampus and cortex using Western blotting analysis. CaMKIl $\alpha$-tTA::TRE-hM4Di bigenic mice at P7 (Fig. 1G-l) as well as in juveniles at P35 (Fig. 1M-O) exhibited robust expression of the HA-tagged hM4Di-DREADD. We then performed Western blotting analysis for the neuronal activity marker c-Fos to examine whether hM4Di-DREADD evoked a reduction in neuronal activity in the hippocampus and cortex, half an hour post$\mathrm{CNO}$ or vehicle treatment to postnatal pups at P7 and juvenile animals at P35. Western blotting analysis, followed by quantitative densitometry for c-Fos protein levels revealed a significant reduction in the hippocampus (Fig. $1 K$ ) and cortex (Fig. $1 L$ ) of PNCNO-treated CaMKII $\alpha$-tTA:: TRE-hM4Di bigenic mouse pups. For the JCNO-treated CaMKII $\alpha$-tTA::TRE-hM4Di bigenic mice at P35, we did not observe a change in the c-Fos protein levels in the hippocampus (Fig. 1Q), but did note a significant decline in C-Fos protein levels in the cortex (Fig. 1R) of the JCNOtreated cohort. Collectively, these results indicate that the expression of HA-tagged hM4Di-DREADD is restricted to 

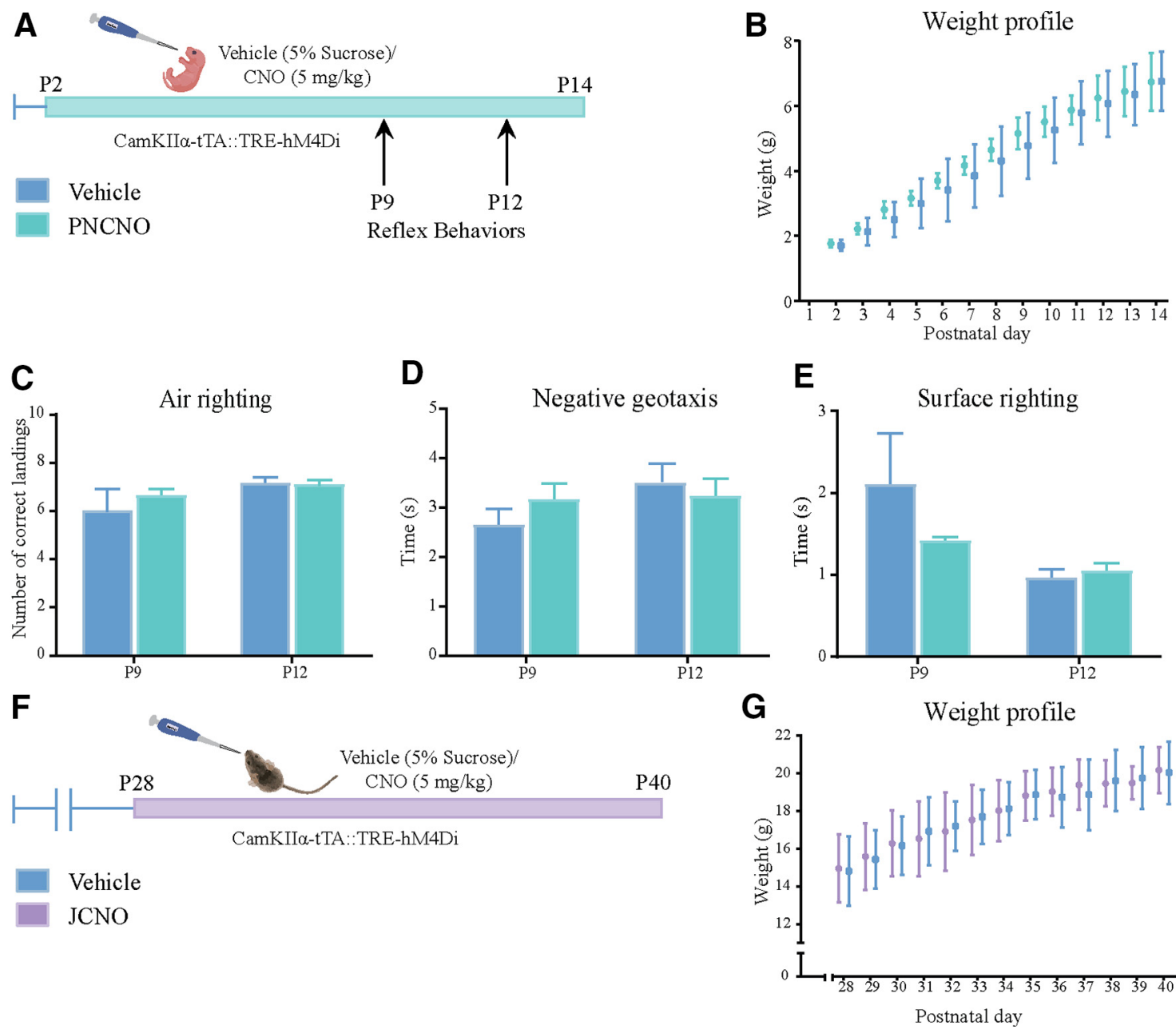

Figure 2. Influence of chronic hM4Di-DREADD-mediated inhibition of CaMKIl $\alpha$-positive forebrain neurons in the early postnatal or juvenile windows on weight and reflex development. $\boldsymbol{A}$, Shown is a schematic for the experimental paradigm for vehicle (5\% sucrose) or CNO $(5 \mathrm{mg} / \mathrm{kg})$ administration in the early postnatal window (P2 to P14) in CaMKIl $\alpha$-tTA::TRE-hM4Di bigenic pups. Pups were assessed for weight gain across the postnatal developmental window and for reflex behaviors on postnatal days 9 and 12 . B, No significant change was observed in the weight profile of $\mathrm{CNO}$-administered pups compared with their vehicle-treated age-matched controls across the duration of CNO treatment from P2 to P14 $(n=6)$. $\boldsymbol{C}-\boldsymbol{E}$, Reflex behaviors were not altered in PNCNO-treated CaMKIll $\alpha$-tTA::TRE-hM4Di bigenic pups compared with vehicle-treated controls at P9 or P12 as assessed by determining the number of correct landings for air righting $(\boldsymbol{C})$, and the time taken for reorientation in both negative geotaxis $(\boldsymbol{D})$ and surface righting $(\boldsymbol{E})$ assays. $\boldsymbol{F}$, Shown is a schematic for the experimental paradigm for vehicle $(5 \%$ sucrose) or CNO $(5 \mathrm{mg} / \mathrm{kg})$ administration in the early juvenile window (P28 to P40) to CaMKIl $\alpha$-tTA::TRE-hM4Di bigenic male mice. G, No significant change was noted in the weight profile of animals fed with CNO $(5 \mathrm{mg} / \mathrm{kg})$ once daily from P28 to P40 compared with their vehicle-treated controls across the duration of drug treatment $(n=5-6 /$ group). Results are expressed as the mean \pm SEM, and groups are compared using the two-tailed, unpaired Student's $t$ test.

forebrain CaMKIl $\alpha$-positive neurons, and that treatment with the DREADD ligand CNO in the early postnatal or juvenile window evokes a decline in activity of within the forebrain regions of the hippocampus and cortex, as indicated by a reduction in protein levels of the neuronal activity marker c-Fos.

\section{Chronic hM4Di-DREADD-mediated inhibition of CaMKIl $\alpha$-positive forebrain excitatory neurons during the early postnatal window does not influence anxiety-like behavior in adulthood in male or female mice}

We set out to examine the behavioral influence of chronic CNO-mediated hM4Di-DREADD inhibition of CaMKIl $\alpha$-positive forebrain excitatory neurons during the early postnatal or juvenile window by orally administering the DREADD ligand CNO $(5 \mathrm{mg} / \mathrm{kg})$ or vehicle to CaMKIl $\alpha$ tTA::TRE-hM4Di bigenic male and female mice once daily from $\mathrm{P} 2$ to $\mathrm{P} 14$ (Fig. 2A; PNCNO) or from P28 to P40 (Fig. $2 F$; JCNO). PNCNO or JCNO treatments did not alter body weight, which was measured across the period of treatment (Fig. 2B,G). PNCNO treatment did not alter the normal ontogeny of reflex behaviors, namely air righting (Fig. $2 C$ ), negative geotaxis (Fig. $2 D$ ), and surface righting (Fig. 2E), in PNCNO-treated CaMKIl $\alpha$-tTA::TRE-hM4Di bigenic mouse pups compared with their vehicle-treated controls.

We next addressed whether a history of hM4Di-DREADDmediated inhibition of CaMKIl $\alpha$-positive forebrain excitatory 
neurons during the early postnatal window alters anxiety-like behavior in adulthood. We subjected CaMKIl $\alpha$-tTA::TREhM4Di bigenic adult male and female mice with a history of PNCNO treatment to a battery of behavioral tests to assess anxiety-like behavior, namely the OFT, EPM test, and LD box test. We do not observe any significant alterations in multiple behavioral measures in the OFT between the vehicle- and PNCNO-treated cohorts in both male and female (Fig. 3B-F) CaMKII $\alpha$-tTA::TRE-hM4Di bigenic mice. We noted a significant PNCNO $\times$ sex interaction $\left(F_{(1,40)}=4.318, p=0.044\right)$ in the total distance traveled (Fig. $3 C$ ) in the OFT arena, with Tukey's post hoc comparisons revealing a significant difference between vehicle-treated male and female CaMKIl $\alpha$ tTA::TRE-hM4Di bigenic mice. No significant interactions between PNCNO and sex were noted for the other measures assessed in the OFT. We did note a significant main effect of sex for percentage of time spent in the center $\left(F_{(1,40)}=21.77\right.$, $p<0.0001$; Fig. $3 D$ ), percentage of the distance traveled in the center $\left(F_{(1,40)}=8.727, p=0.0052\right.$; Fig. $\left.3 E\right)$, and the number of entries to the center $\left(F_{(1,40)}=11.07, p=0.002\right.$; Fig. $\left.3 F\right)$. We noted no significant effect of PNCNO for any of the behavioral measures assessed in the OFT.

We did not observe any significant PNCNO $\times$ sex interaction for the multiple behavioral measures assessed in the EPM test (Fig. 3G-M). We observed a significant main effect of sex for the percentage of time spent in closed $\operatorname{arms}\left(F_{(1,45)}=76.53, p<0.0001\right.$; Fig. $\left.3 H\right)$ and the percentage of time spent in open arms $\left(F_{(1,45)}=12.98, p=0.0008\right.$; Fig. 3/), as well as for the number of entries to closed arms $\left(F_{(1,45)}=14.38, p=0.0004\right.$; Fig. $\left.3 L\right)$ and open arms $\left(F_{(1,45)}\right.$ $=290.7, p<0.0001$; Fig. 3M), but not for the measures of percentage of distance traveled in closed (Fig. 3J) and open (Fig. 3K) arms. We noted no significant effect of PNCNO for any of the behavioral measures assessed in the EPM test. We next assessed the behavior of vehicleand PNCNO-treated CaMKII $\alpha$-tTA::TRE-hM4Di bigenic adult male and female mice on the LD box. We noted no significant PNCNO $\times$ sex interactions for either the percentage of time or the number entries in the light box. We noted a significant main effect of sex for percentage of time spent in the light box $\left(F_{(1,42)}=40.27, p<0.0001\right.$; Fig. 30 ), and a significant main effect of PNCNO for the number of entries to the light box $\left(F_{(1,42)}=5.227, p=0.027\right.$; Fig. $3 P$ ). Together, these findings indicate that PNCNOmediated, chronic hM4Di-DREADD inhibition of CaMKIl $\alpha$ positive forebrain excitatory neurons during the early postnatal window does not appear to significantly influence anxiety-like behavior in adulthood on the OFT, EPM test, and LD test in both male and female CaMKII $\alpha$-tTA:: TRE-hM4Di bigenic mice. However, we do note robust main effects of sex on multiple measures across distinct anxiety-related behavioral tasks.

\section{Chronic hM4Di-DREADD-mediated inhibition of CaMKIl $\alpha$-positive forebrain excitatory neurons during the early postnatal window does not influence adult despair-like behavior in male and female mice or sensorimotor gating responses in male mice}

We next addressed whether a history of hM4Di-DREADDmediated inhibition of CaMKIl $\alpha$-positive forebrain excitatory neurons during the early postnatal window alters despairlike behavior in adulthood on the FST (Fig. 4A-D). PNCNO treatment did not alter either the percentage of immobility time or the number of immobility events, indicating no change in despair-like behavior in CaMKII $\alpha$-tTA::TREhM4Di bigenic adult male and female mice. We did not observe any significant PNCNO $\times$ sex interaction for the percentage of immobility time (Fig. 4C) or the number of immobility events (Fig. 4D). We did note a significant effect of sex on the number of immobility events $\left(F_{(1,42)}=\right.$ $18.45, p=0.0001)$. We noted no significant main effect of PNCNO on either of the measures assessed in the FST. We also performed TST to assess despair-like behavior in adult vehicle- and PNCNO-treated CaMKII $\alpha$-tTA::TREhM4Di bigenic male mice and observed no change in despair-like behavior (percentage of immobility time: vehicle-treated CaMKII $\alpha$-tTA::TRE-hM4Di bigenic adult male mice $=60.54 \pm 4.5, n=8$; PNCNO-treated CaMKII $\alpha$-tTA:: TRE-hM4Di bigenic adult male mice $=62.56 \pm 2.63, n=9$; results are expressed as the mean \pm SEM).

Disruption of excitation/inhibition balance in the neocortex has been linked to altered schizoaffective behavior in adulthood (Yizhar et al., 2011; Fenton, 2015; Marín, 2016; Anticevic and Lisman, 2017; Pati et al., 2020). We sought to address whether chronic CNO-mediated hM4Di inhibition of CaMKII $\alpha$-positive forebrain excitatory neurons in the early postnatal window resulted in any change in sensorimotor gating behavior in adulthood. To measure changes in sensorimotor gating, we subjected PNCNOtreated CaMKII $\alpha$-tTA::TRE-hM4Di bigenic male mice and their respective vehicle-treated control groups to the PPI paradigm (Fig. 4E). We noted no significant difference in the percentage of prepulse inhibition, at all prepulse tones tested above the background noise, between the PNCNO-treated CaMKII $\alpha$-tTA::TRE-hM4Di bigenic male mice and their respective vehicle-treated controls (Fig. $4 G$ ). However, we did observe a significant increase in basal startle response in the CaMKII $\alpha$-tTA::TRE-hM4Di bigenic male mice with a history of PNCNO treatment when compared with their vehicle-treated controls (Fig. 4F). Collectively, these results indicate that chronic hM4DiDREADD-mediated chemogenetic inhibition of CaMKII $\alpha$ positive forebrain excitatory neurons during the early postnatal does not alter despair-like behavior on the FST or TST in adulthood, and does not result in any significant change in sensorimotor gating, but may evoke perturbed baseline startle responses in the PNCNO-treated group.

\section{Chronic hM4Di-DREADD-mediated inhibition of} CaMKIl $\alpha$-positive forebrain excitatory neurons during the juvenile window does not influence anxiety, despair, or sensorimotor gating behavior in adulthood

We examined whether chronic CNO-mediated hM4DiDREADD inhibition of CaMKII $\alpha$-positive forebrain excitatory neurons during the juvenile window (P28 to P40) alters anxiety-like behavior in adulthood. We subjected CaMKII $\alpha$-tTA::TRE-hM4Di bigenic adult male mice with a history of JCNO treatment to a battery of behavioral tests commencing 2 months after the cessation of CNO treatment. We examined anxiety-like behavior on the OFT, 
A
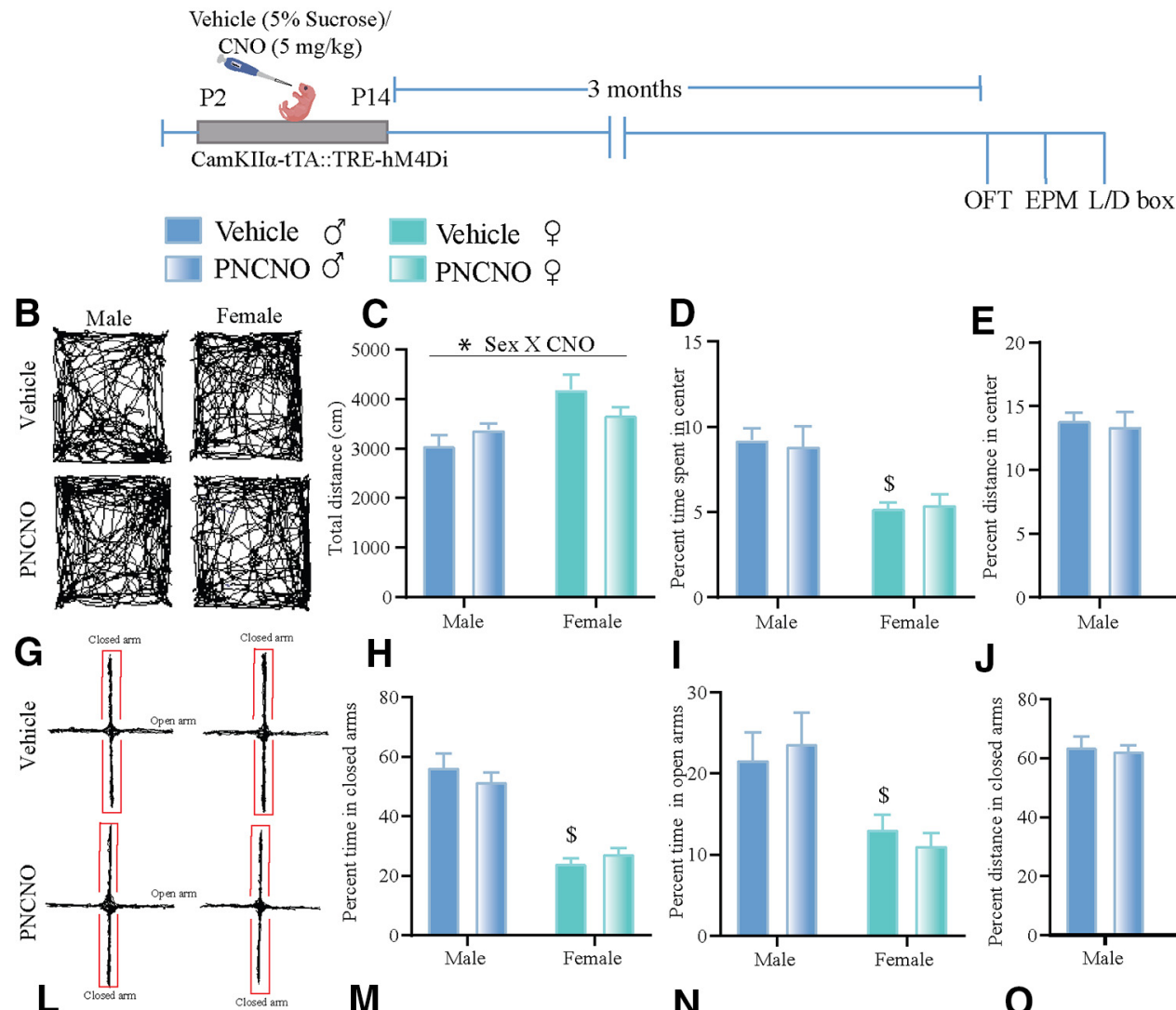

$\mathrm{H}$
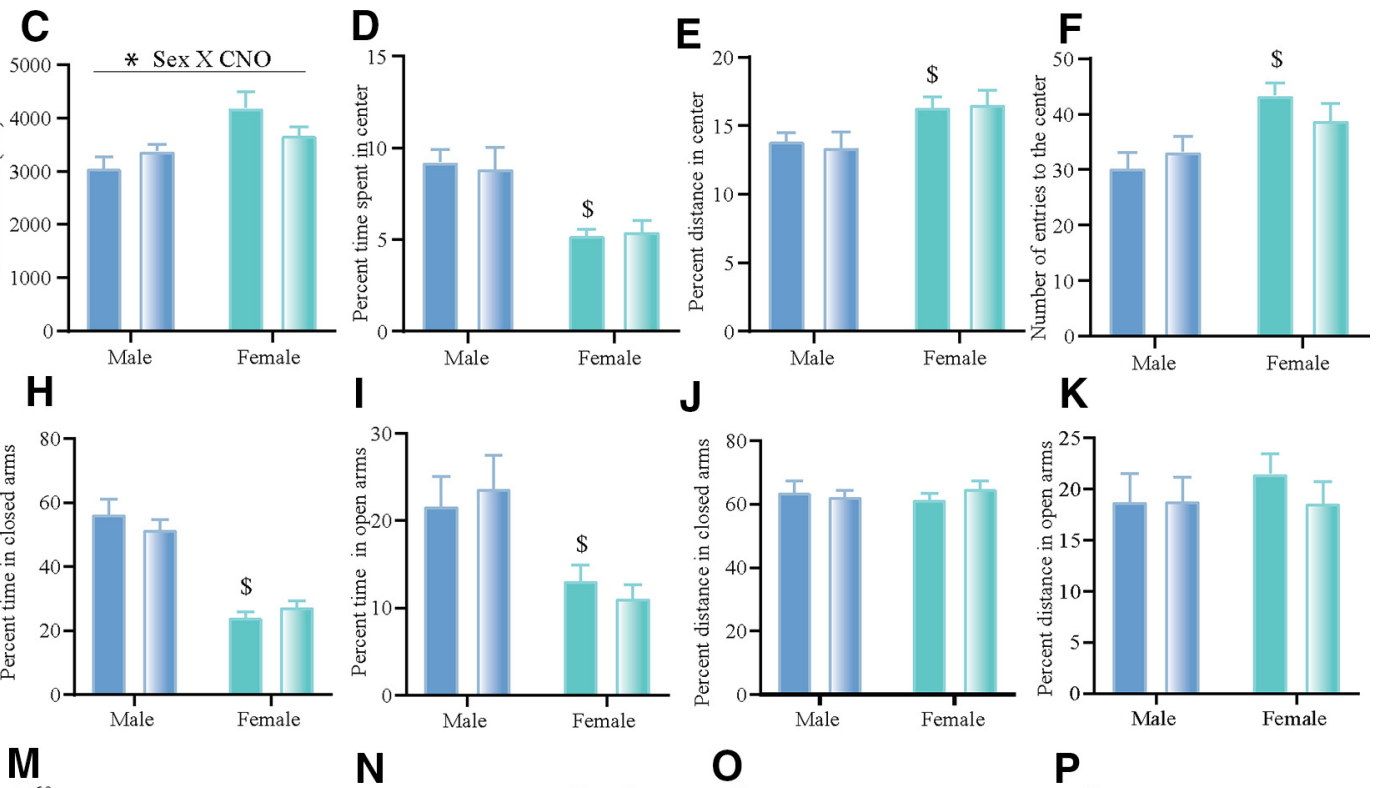

J
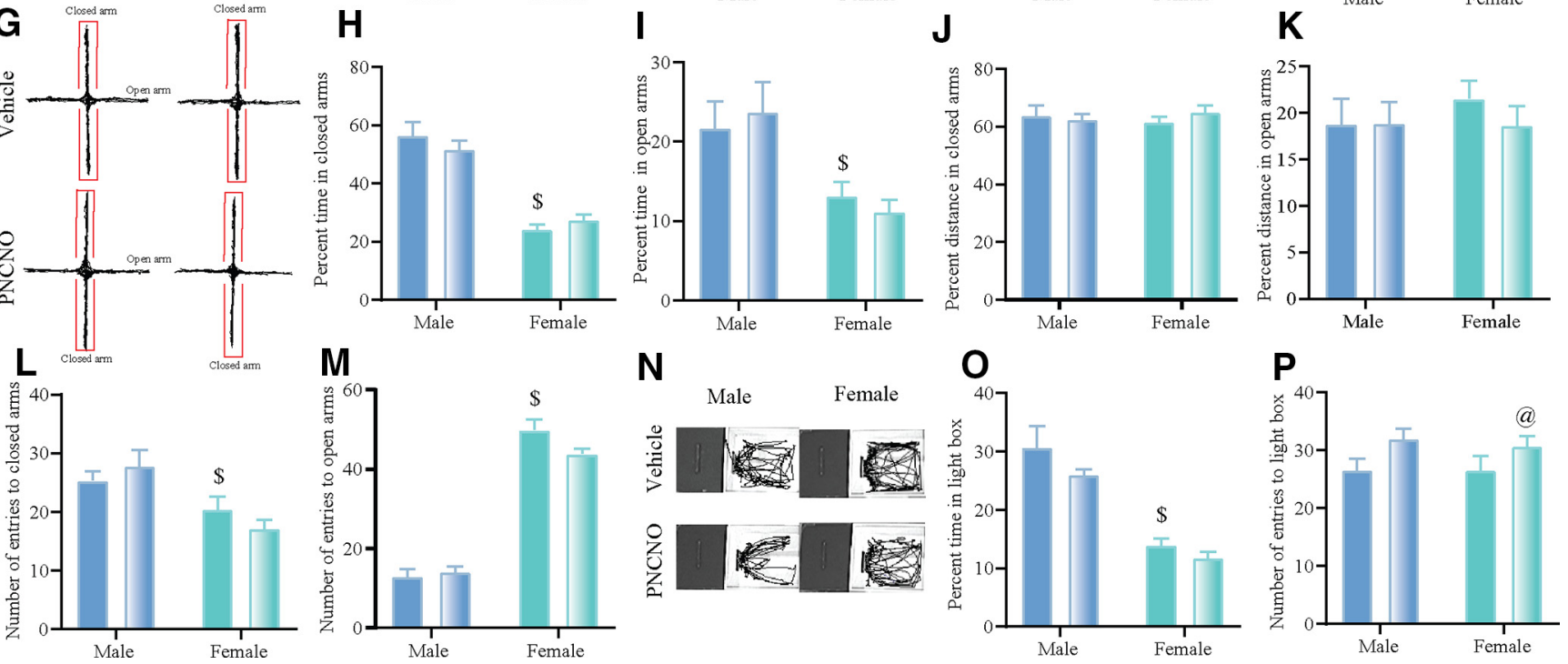

Figure 3. Chronic hM4Di-DREADD-mediated inhibition of CaMKII $\alpha$-positive forebrain excitatory neurons during the early postnatal window does not influence anxiety-like behavior in adulthood in CaMKII $\alpha$-tTA::TRE-hM4Di bigenic mice. $\boldsymbol{A}$, Shown is a schematic for the experimental paradigm for vehicle (5\% sucrose) or CNO $(5 \mathrm{mg} / \mathrm{kg})$ administration in the early postnatal window (P2 to P14) to CaMKII $\alpha$-tTA::TRE-hM4Di bigenic pups, which were then assessed for anxiety-like behaviors 3 months postcessation of CNO treatment in adulthood. B, Shown are representative tracks for vehicle-treated (top panels) and PNCNO-treated (bottom panels) CaMKII $\alpha$-tTA::TRE-hM4Di bigenic male and female mice in the open field arena. $\boldsymbol{C}$, Two-way ANOVA indicated a PNCNO $\times$ sex interaction for total distance moved in the OFT arena, with post hoc Tukey's analysis revealing a significant difference between the vehicle-treated female and male CaMKII $\alpha$-tTA::TRE-hM4Di bigenic mice. $\boldsymbol{D}-\boldsymbol{F}$, We noted significant main effects of sex for the percentage of time spent in the center $(\boldsymbol{D})$, the percentage of the distance traveled in the center $(\boldsymbol{E})$, and the total number of entries to the center of the open field arena $(\boldsymbol{F}) . n=10$ (males) and $n=10$ (females) for vehicle-treated CaMKIll $\alpha$-tTA::TRE-hM4Di bigenic mice; $n=12$ (males), $n=12$ (females) for PNCNO-treated CaMKII $\alpha$-tTA::TRE-hM4Di bigenic mice. G, Shown are representative tracks for vehicle-treated (top panels) and PNCNO-treated (bottom panels) CaMKII $\alpha$-tTA::TRE-hM4Di bigenic male and female mice in the elevated plus maze. $\boldsymbol{H}-\boldsymbol{M}$, We noted a significant main effect of sex for the percentage of time in the closed $(\boldsymbol{H})$ and open $(\boldsymbol{I})$ arms of the plus maze, and for the number of entries to the closed $(\boldsymbol{L})$ and open $(\boldsymbol{M})$ arms, but not for the percentage of distance traveled in closed $(\boldsymbol{J})$ or open $(\boldsymbol{K})$ arms. $n=14$ (males) and $n=10$ (females) for vehicle-treated CaMKII $\alpha$-tTA::TRE-hM4Di bigenic mice; $n=12$ (males) and $n=12$ (females) for PNCNO-treated CaMKIl $\alpha$-tTA::TRE-hM4Di bigenic mice. $\boldsymbol{N}$, Shown are representative tracks for vehicle-treated (top panels) and PNCNO-treated (bottom panels) CaMKIl $\alpha$-tTA::TRE-hM4Di bigenic mice in the LD box. No significant interaction of PNCNO $\times$ sex was noted in the LD box. $\boldsymbol{O}, \boldsymbol{P}$, However, we did observe a significant main effect of sex in the total time spent in the light box $(\mathbf{O})$, and a significant main effect of PNCNO treatment on the total number of entries into the light chamber of the LD box $(\boldsymbol{P}) . n=14$ (males) and $n=10$ (females) for vehicle-treated CaMKIl $\alpha$-tTA::TRE-hM4Di bigenic mice; $n=12$ (males) and $n=12$ (females) PNCNO-treated CaMKIl $\alpha$-tTA::TRE-hM4Di bigenic mice. Results are expressed as the mean \pm SEM, and groups are compared using two-way ANOVA, followed by the Tukey's post hoc comparison test when a significant PNCNO $\times$ sex interaction was noted $\left({ }^{*} p<0.05\right)$. The main effects of sex are indicated as ${ }^{\$} p<0.05$; the main effects of CNO treatment are indicated as ${ }^{\circledR} p<0.05$. 
A

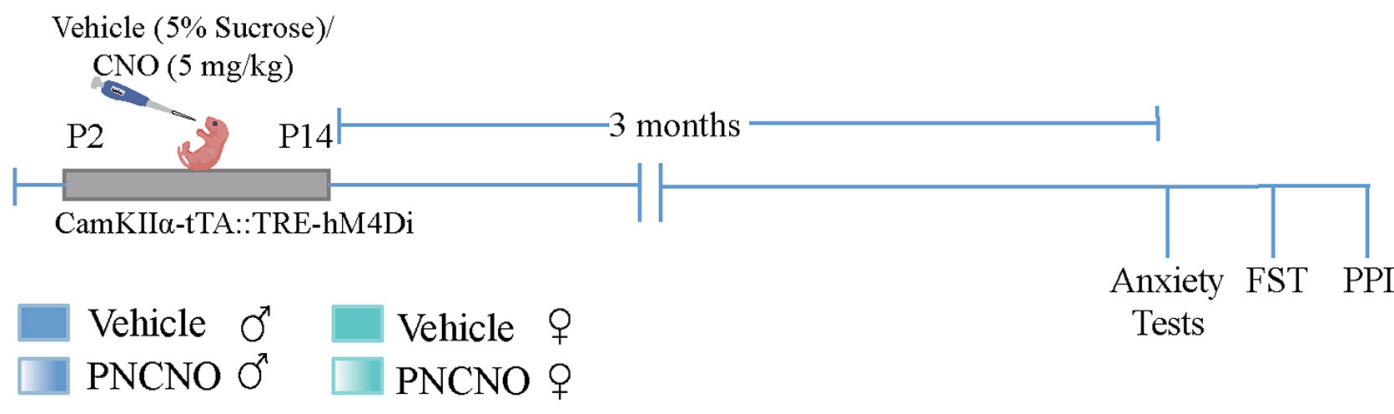

B

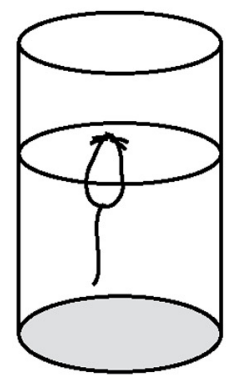

E
C

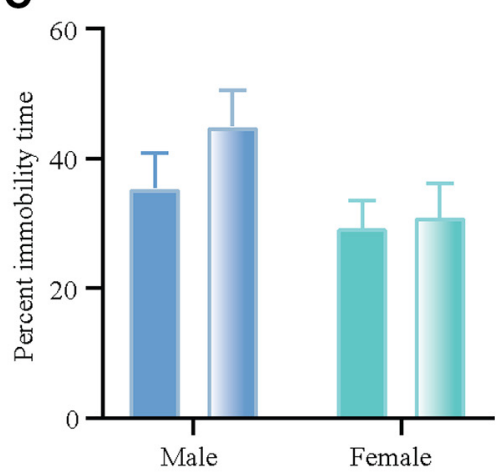

D

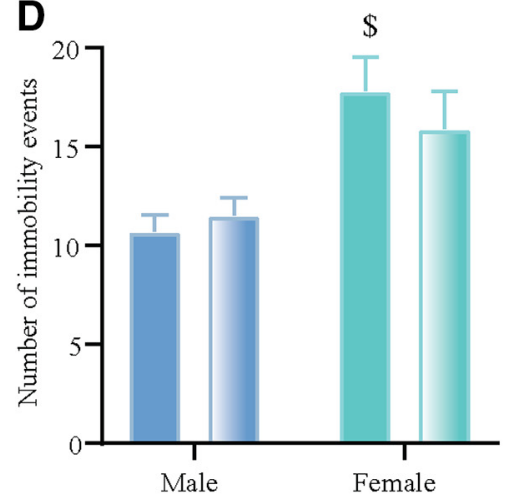

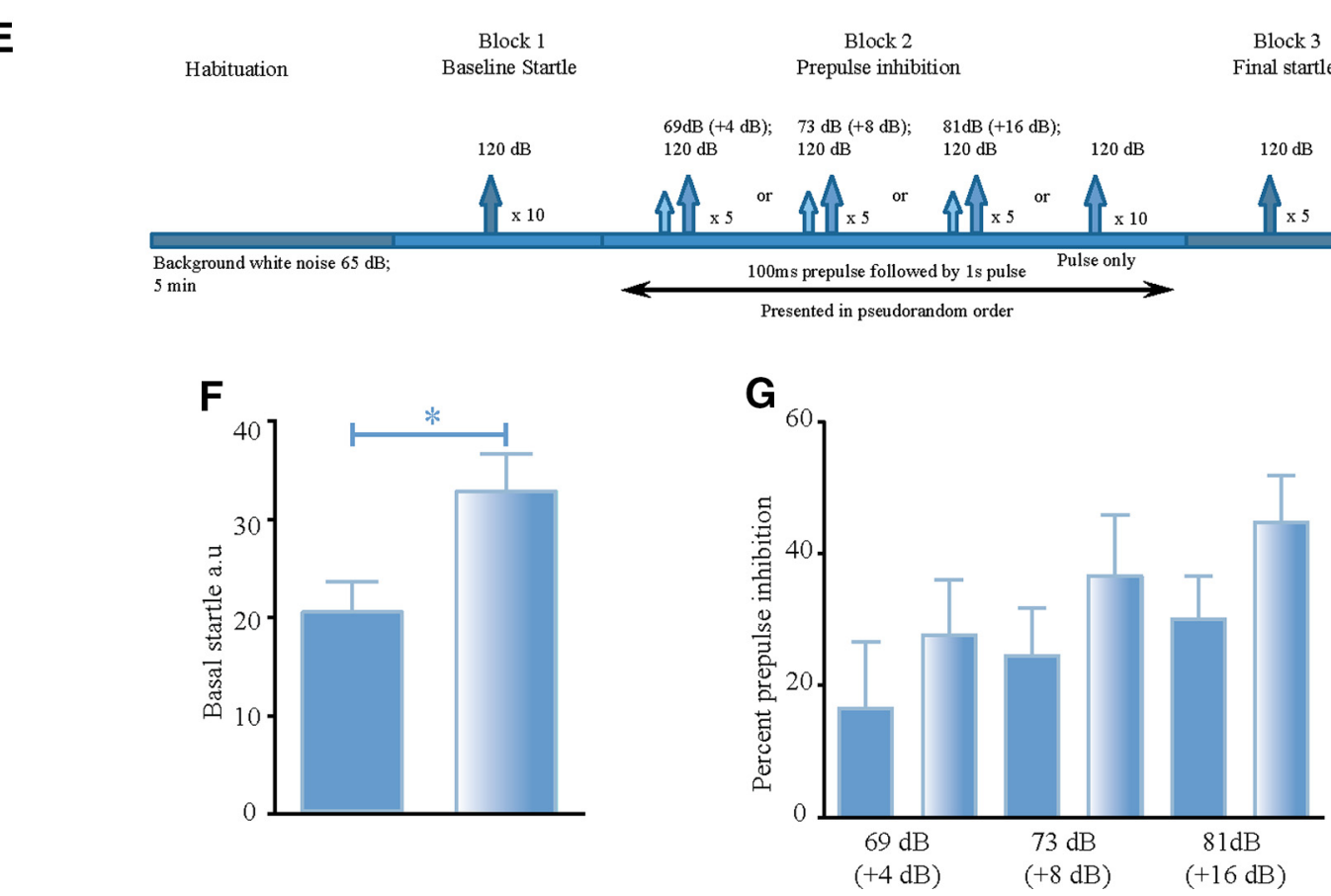

Figure 4. Chronic chemogenetic inhibition of CaMKII $\alpha$-positive forebrain excitatory neurons during the early postnatal window does not influence despair-like behavior or sensorimotor gating responses in adult mice. $\boldsymbol{A}$, Shown is a schematic for the experimental paradigm for vehicle ( $5 \%$ sucrose) or CNO $(5 \mathrm{mg} / \mathrm{kg})$ administration in the early postnatal window (P2 to P14) to CaMKIl $\alpha$-tTA::TREhM4Di bigenic pups, which were then assessed for despair-like behavior in adulthood using the FST and sensorimotor gating responses (PPI). B, Shown is a schematic for the FST tank. $\boldsymbol{C}, \boldsymbol{D}$, We observed no significant PNCNO $\times$ sex interactions for either the percentage of immobility time $(\boldsymbol{C})$ or the total number of immobility events $[\boldsymbol{D} ; n=14$ (males), $n=10$ (females) for vehicle-treated CaMKII $\alpha$-tTA::TRE-hM4Di bigenic mice; $n=12$ (males), $n=10$ (females) for PNCNO-treated CaMKII $\alpha$-tTA::TRE-hM4Di bigenic mice]. $\boldsymbol{D}$, We did note a significant main effect of sex for the number of immobility events. $\boldsymbol{E}$, Shown is a schematic for the protocol used for PPI to assess sensorimotor gating responses in adult male mice. PPI testing was conducted as described in Materials and 
continued

Methods with basal startle determined following habituation, and PPI determined for $+4 \mathrm{~dB}(69 \mathrm{~dB}),+8 \mathrm{~dB}(73 \mathrm{~dB})$, and $+16 \mathrm{~dB}$ $(81 \mathrm{~dB})$ above background noise $(65 \mathrm{~dB})$, followed by exposure to $120 \mathrm{~dB}$ for final startle. $\boldsymbol{F}$, PNCNO-treated adult CaMKIll $\alpha$-tTA:: TRE-hM4Di bigenic male mice show a significant increase in basal startle response compared with vehicle-treated controls. $G$, No significant differences were noted in sensorimotor gating between vehicle- and PNCNO-treated CaMKII $\alpha$-tTA::TRE-hM4Di bigenic male mice ( $n=10$ group). Results were subjected to two-way ANOVA, followed by the Tukey's post hoc comparisons test for experiments with four treatment groups (main effects of sex are indicated as ${ }^{\$} p<0.05$ ), and by the two-tailed, unpaired Student's $t$ test for experiments with two treatment groups. Results are expressed as the mean \pm SEM. ${ }^{*} p<0.05$ compared with the vehicle-treated controls.

EPM test, and LD test. JCNO-treated CaMKII $\alpha$-tTA::TREhM4Di bigenic adult male mice did not exhibit any difference in anxiety-like behavior on these behavioral tasks (Fig. 5A). On the OFT, we noted no change in the total distance traveled in the OFT arena (Fig. 5B,C), as well as in the percentage of time spent in the center (Fig. 5D), the percentage of distance traveled in the center (Fig. 5E), or in the total number of entries to the center of the OFT arena (Fig. 5F). We also observed no significant differences in behavior on the EPM test (Fig. $5 G-M$ ), with no change noted for the percentage of time spent in closed arms (Fig. $5 H$ ) or open arms (Fig. $5 /$ ), as well as the percentage of distance traveled in closed arms (Fig. $5 \mathrm{~J}$ ) or open arms (Fig. $5 K$ ). The total number of entries to both the closed (Fig. 5L) and open arms (Fig. 5M) was also unchanged across vehicle- and JCNO-treated CaMKII $\alpha$ tTA::TRE-hM4Di bigenic adult male mice. Behavioral measures assessed on the LD box test (Fig. $5 \mathrm{~N}-\mathrm{P}$ ) were also not altered between vehicle- and JCNO-treated CaMKII $\alpha$-tTA::TRE-hM4Di bigenic adult male cohorts, with no difference noted for either the percentage of time spent in the light box (Fig. 5O) or the number of entries to the light box (Fig. 5P). Further, we examined whether CaMKII $\alpha$-tTA::TRE-hM4Di bigenic adult male mice with a history of JCNO treatment differed from their vehicletreated controls on the FST (Fig. 5Q-S) and TST. JCNOtreated CaMKII $\alpha$-tTA::TRE-hM4Di bigenic adult males did not show any significant differences in the percentage of immobility time (Fig. 5R) or the number of immobility events (Fig. 5S) on the FST. We also noted no significant differences in the percentage of immobility time on the TST between JCNO-treated CaMKII $\alpha$-tTA::TRE-hM4Di bigenic adult male and the vehicle-treated cohort (percent of immobility time: vehicle-treated CaMKII $\alpha$-tTA::TRE$\mathrm{hM} 4 \mathrm{Di}$ bigenic adult male mice $=64.15 \pm 5.56, n=9$; JCNO-treated CaMKII $\alpha$-tTA::TRE-hM4Di bigenic adult male mice $=60.52 \pm 2.32, n=9$; results are expressed as the mean \pm SEM). Collectively, these results indicate that chronic hM4Di-DREADD-mediated chemogenetic inhibition of CaMKII $\alpha$-positive forebrain excitatory neurons during either the early postnatal or juvenile window does not alter anxiety- or despair-like behavior in adulthood.

We next sought to address whether chronic CNO-mediated $\mathrm{hM} 4 \mathrm{Di}$ inhibition of CaMKIl $\alpha$-positive forebrain excitatory neurons in the juvenile window resulted in any change in sensorimotor gating behavior in adulthood. To measure changes in sensorimotor gating, we subjected JCNO-treated CaMKII $\alpha$-tTA::TRE-hM4Di bigenic male mice and their respective vehicle-treated control groups to the PPI paradigm (Fig. 5T). We noted no significant difference in basal acoustic startle (Fig. $5 U$ ) or the percentage of prepulse inhibition (Fig. $5 \mathrm{~V}$ ) at all prepulse tones tested above the background noise in the JCNOtreated CaMKII $\alpha$-tTA::TRE-hM4Di bigenic male mice and their respective vehicle-treated controls. These findings indicate that chronic CNO-mediated hM4Di-DREADD inhibition of CaMKII $\alpha$-positive forebrain excitatory neurons during the juvenile window does not result in any significant change in sensorimotor gating.

\section{Discussion}

Our findings indicate that chronic hM4Di-DREADDmediated inhibition of CaMKII $\alpha$-positive forebrain excitatory neurons during the early postnatal or juvenile windows of life does not appear to influence the development of anxiety- or despair-like behavior or alter sensorimotor gating in adulthood. Preclinical studies using rodent models indicate that the first 2 weeks of life represent a critical period window (Baram et al., 1997), wherein the early stress of maternal separation (MS; Benekareddy et al., 2011; Kalinichev et al., 2002; De Melo et al., 2018; Teissier et al., 2020) or pharmacological perturbations that elevate serotonin levels, such as postnatal selective serotonin reuptake inhibitor (SSRI) administration (Ansorge et al., 2004; Ko et al., 2014; Rebello et al., 2014; Sarkar et al., 2014; Soiza-Reilly et al., 2019), can result in the life-long programming of persistent mood-related behavioral changes. Converging evidence across diverse models of early stress has implicated perturbations in G-protein-coupled receptor (GPCR) signaling during these critical periods in the establishment and eventual emergence of disrupted anxiodepressive behaviors (Vinkers et al., 2010; Benekareddy et al., 2011; Sarkar et al., 2014; Teissier et al., 2015; Soiza-Reilly et al., 2019; Pati et al., 2020). This has led to a hypothesis that a balance between $\mathrm{G}_{\mathrm{q}}$ - and $\mathrm{G}_{\mathrm{i}}$-mediated GPCR signaling within neocortical brain regions during these early developmental windows may be important to shaping the development of trait anxiety and behavioral despair (Lambe et al., 2011; Tiwari et al., 2021). A recent study has shown that enhanced $G_{q}$ signaling via chemogenetic hM3Dq-DREADD-mediated activation of CaMKII $\alpha$-positive forebrain excitatory neurons during the postnatal, but not the juvenile or adult, temporal windows results in long-lasting increases in anxiety- and despair-like behavior, accompanied by perturbed sensorimotor gating and PPI deficits (Pati et al., 2020). While several studies have used pharmacological or genetic perturbation studies to examine the contribution of $\mathrm{G}_{\mathrm{i}}$-coupled GPCRs, in particular the 5- $\mathrm{HT}_{1 \mathrm{~A}}$ receptor (Gross et al., 2002; Vinkers et al., 2010; Richardson-Jones et al., 2010, 2011; Garcia-Garcia et al., 2014; Sarkar et al., 2014) during postnatal life in programming mood-related behavior, 

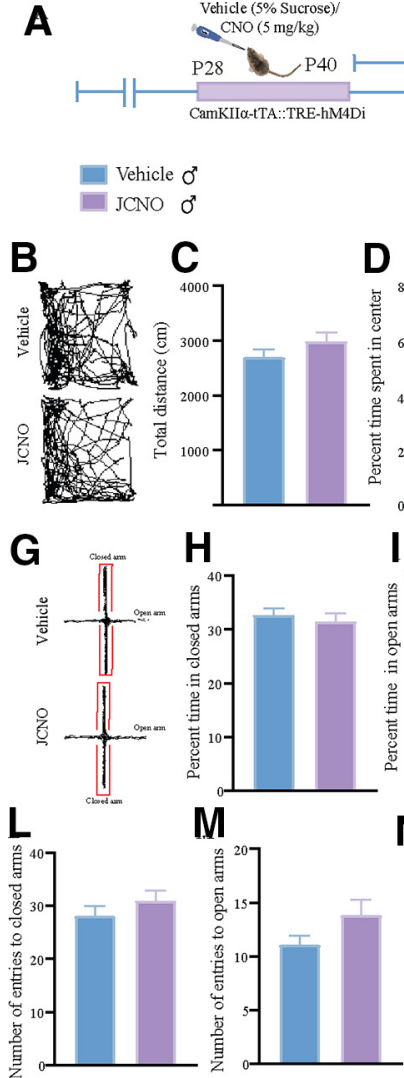

E
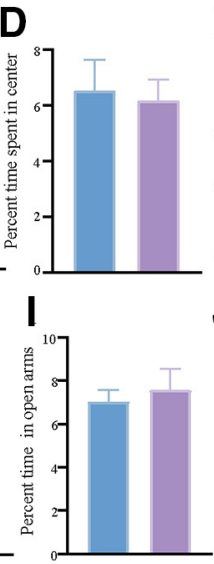

N

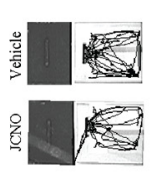

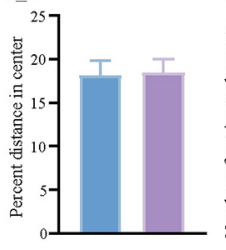
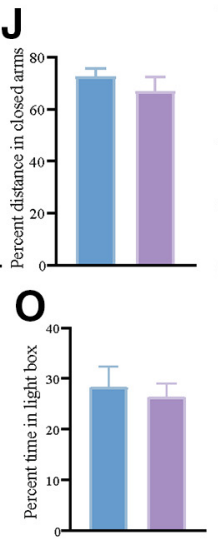

F

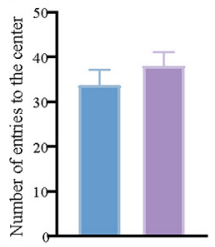

K
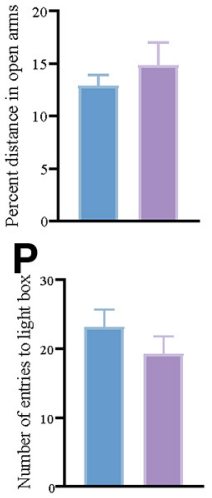

Q

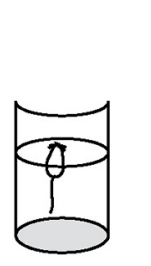

R

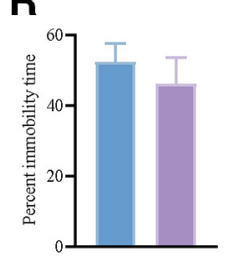

S

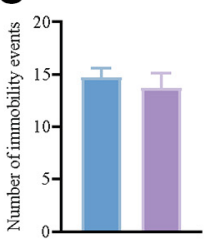

T
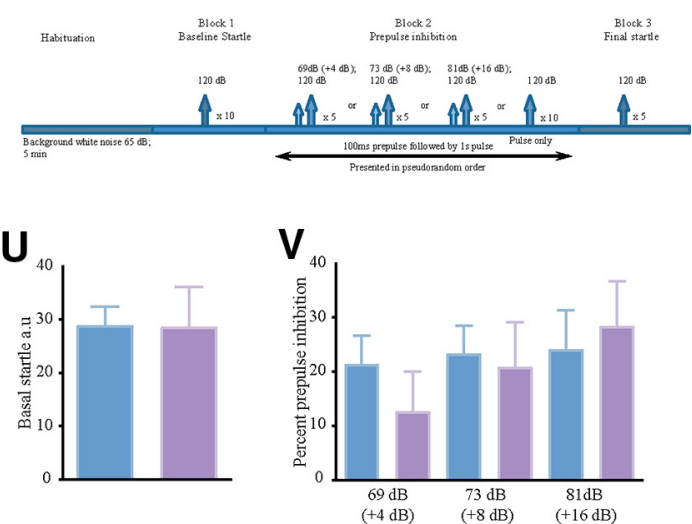

Figure 5. Chronic hM4Di-DREADD-mediated inhibition of CaMKIl $\alpha$-positive forebrain excitatory neurons during the juvenile window does not influence anxiety, despair, or sensorimotor gating behavior in adulthood in CaMKIl $\alpha$-tTA::TRE-hM4Di bigenic male mice. $\boldsymbol{A}$, Shown is a schematic for the experimental paradigm for vehicle ( $5 \%$ sucrose) or CNO $(5 \mathrm{mg} / \mathrm{kg})$ administration in the juvenile window (P28 to P40) to CaMKII $\alpha$-tTA::TRE-hM4Di bigenic mice, which were then assessed for anxiety-like behaviors 2 months postcessation of CNO treatment in adulthood in the male cohort. $\boldsymbol{B}$, Shown are representative tracks for vehicle-treated (top panel) and JCNO-treated CaMKII $\alpha$-tTA::TRE-hM4Di bigenic male mice (bottom panel) in the open field arena. C-F, No significant difference was noted between vehicle- and JCNO-treated male mice in the total distance traveled in the arena $(\boldsymbol{C})$, the percentage of time spent in the center $(\boldsymbol{D})$, the percentage of distance traveled in the center $(\boldsymbol{E})$, or the total number of entries to the center of the open field arena ( $\boldsymbol{F} ; n=18$ for vehicle-treated male mice; $n=16$ for JCNO-treated male mice). $\boldsymbol{G}$, Shown are representative tracks for vehicle-treated (top panel) and JCNO-treated CaMKII $\alpha$-tTA::TRE-hM4Di bigenic male mice (bottom panel) in the elevated plus maze. $\boldsymbol{H}$ $\boldsymbol{M}$, No significant difference was observed between vehicle- and JCNO-treated male mice in the percentage of time spent in the closed $(\boldsymbol{H})$ or open $(\boldsymbol{I})$ arms of the EPM, as well as the percentage of distance traveled in closed $(\boldsymbol{J})$ or open $(\boldsymbol{K})$ arms, and for the number of entries to the closed $(\boldsymbol{L})$ or open $(\boldsymbol{M})$ arms $(n=18$ for vehicle-treated male mice; $n=16$ for JCNO-treated male mice). $\boldsymbol{N}$, Shown are representative tracks for vehicle-treated (top panel) and JCNO-treated (bottom panel) CaMKII $\alpha$-tTA::TRE-hM4Di bigenic male mice in the LD box. $\boldsymbol{O}, \boldsymbol{P}$, No significant difference was noted between vehicle- and JCNO-treated male mice in either the total time spent in $(\mathbf{O})$ or the total number of entries $(\boldsymbol{P})$ into the light chamber of the LD box $(n=18$ for vehicle-treated male mice; $n=16$ for JCNO-treated male mice). $\boldsymbol{Q}$, Shown is a schematic for the FST tank. $\boldsymbol{R}, \boldsymbol{S}$, No significant difference was noted between vehicleand PNCNO-treated male mice for the percentage of immobility time $(\boldsymbol{R})$ or for the total number of immobility events $(\boldsymbol{S} ; n=11$ for vehicle-treated male mice; $n=11$ for JCNO-treated male mice). $\boldsymbol{T}$, Shown is a schematic for the protocol used for PPI to assess sensorimotor gating responses in adult male mice. PPI testing was conducted as described in Materials and Methods with basal startle determined following habituation, and PPI determined for $+4 \mathrm{~dB}(69 \mathrm{~dB})$, $+8 \mathrm{~dB}(73 \mathrm{~dB})$, and $+16 \mathrm{~dB}(81 \mathrm{~dB})$ above background noise $(65 \mathrm{~dB})$, followed by exposure to $120 \mathrm{~dB}$ for final startle. $\boldsymbol{U}$, Basal startle response in JCNO-treated CaMKIl $\alpha$-tTA::TRE-hM4Di bigenic male mice was unaltered compared with vehicle-treated CaMKIl $\alpha$-tTA::TRE-hM4Di bigenic male controls. $\boldsymbol{V}$, CaMKIl $\alpha$-tTA:: TRE-hM4Di bigenic male mice with a history of JCNO treatment did not show any change in PPI compared with the vehicle-treated controls ( $n=10$ for vehicle; $n=9$ for JCNO male mice). Results are expressed as the mean \pm SEM, and groups are compared using the two-tailed, unpaired Student's $t$ test.

this has not been directly tested using a chemogeneticbased approach to perturb $\mathrm{G}_{\mathrm{i}}$ signaling in CaMKIl $\alpha$-positive forebrain excitatory neurons. Based on prior evidence that pharmacological blockade (Vinkers et al., 2010; Sarkar et al., 2014) or genetic loss of function of the $\mathrm{G}_{\mathrm{i}}-$ coupled $5-\mathrm{HT}_{1 \mathrm{~A}}$ receptor results in enhanced anxiety- and despair-like behavior (Gross et al., 2002; Richardson-Jones et al., 2010, 2011), a working hypothesis would suggest the possibility that enhancing $\mathrm{G}_{\mathrm{i}}$ signaling in CaMKII $\alpha$-positive forebrain excitatory neurons during the postnatal window might evoke a decline 
in anxiety- and despair-like behaviors in adulthood. Prior evidence indicates that transient hM4Di-DREADD inhibition of the amygdala in infant rhesus monkeys has long-lasting effects on emotionality, with a decline noted in fear and anxiety responses (Raper et al., 2019). A study also shows that constitutive overexpression of the $\mathrm{G}_{\mathrm{i}}$-coupled $5-\mathrm{HT}_{1 \mathrm{~A}}$ receptors (Kusserow et al., 2004) can program decreased anxiety-like behavior in adulthood. This differs from the pharmacological studies, wherein 5- $\mathrm{HT}_{1 \mathrm{~A}}$ receptor stimulation in the postnatal window using the agonist 8-OH-DPAT alone does not modulate anxiety-like behavior, but can increase despair-like behavior in adulthood (Ishikawa and Shiga, 2017), whereas blockade of $5-\mathrm{HT}_{1 \mathrm{~A}}$ receptors in early postnatal life with the selective antagonist WAY 100635 evokes increased anxietylike behavior (Vinkers et al., 2010; Sarkar et al., 2014). However, there is a paucity of literature that addresses directly whether broad alteration of $G_{i}$ signaling within forebrain neurocircuits during the postnatal temporal window contributes to the programming of altered mood-related behaviors. The results of the present study clearly demonstrate that $\mathrm{G}_{\mathrm{i}}$ mediated inhibition of forebrain excitatory neurons using the hM4Di-DREADD during either the postnatal (P2 to P14) or juvenile (P28 to $\mathrm{P} 40$ ) windows does not evoke any significant behavioral change on conflict-based tasks assessing anxiety-like behavior, namely the OFT, EPM test, and LD avoidance test in adulthood. Further, we also noted no change in despair-like behavior on the TST and FST or in sensorimotor gating behavior on the PPI in adulthood.

The expression of the hM4Di-DREADD was restricted to the neocortex and hippocampus, as indicated by both Western blotting and immunofluorescence analysis, and the hM4Di-DREADD expression was restricted to CaMKIl $\alpha$-positive forebrain excitatory neurons and was not observed in PV-positive inhibitory interneurons or GFAP-positive astrocytes (Fig. 1). Western blotting analysis for the neuronal activity marker c-Fos indicates that, as reported previously (Vetere et al., 2017; Salvi et al., 2019), treatment with the DREADD ligand $\mathrm{CNO}$ results in reduced neuronal activity in the forebrain of CaMKIl $\alpha$-tTA::TRE-hM4Di bigenic mice, as indicated by a decline in c-fos protein levels. However, one of the caveats of using a Western blotting approach to examine total c-Fos protein levels within the neocortex and hippocampus is that one loses the information of the specific classes of cells exhibiting a c-Fos reduction. While our biochemical studies do indicate a reduction in total c-Fos protein level on CNO-mediated $\mathrm{hM}$ 4Di DREADD stimulation, further electrophysiological and immunofluorescence studies would aid in uncovering the precise cell types targeted in the neocortex and hippocampus. We found that the administration of the exogenous DREADD ligand CNO in the postnatal or juvenile window did not appear to alter the growth and development of animals, based on observations of no weight change in animals, as well as a normal ontogenic development of reflex behaviors in CNO-treated CaMKIl $\alpha$-tTA::TRE-hM4Di bigenic rat pups. This suggests that enhanced hM4Di-DREADD-mediated inhibition of CaMKIll $\alpha$-positive forebrain excitatory neurons in postnatal life does not appear to influence the emergence of critical reflexes such as air-righting, negative geotaxis, and surface righting. This is in agreement with prior studies that indicate that the DREADD agonist CNO during the postnatal window does not appear to influence the emergence of key developmental milestones (Pati et al., 2020).

A change in excitation-inhibition balance during critical developmental time windows, with a shift toward enhanced excitation of forebrain pyramidal neurons and a commensurate reduction in inhibitory tone, has been posited to play a crucial role in the programming of life-long perturbations of mood-related behaviors in several neurodevelopmental disorder models (Yizhar et al., 2011; Fenton, 2015; Nelson and Valakh, 2015; Tatti et al., 2017; Sohal and Rubenstein, 2019). Indeed, hyperexcitation of Emx1-positive neurons from P4 to P14 in the neocortex using either a noninvasive bioluminescent chemogenetics approach (Medendorp et al., 2021) or hM3Dq-DREADDmediated activation of CaMKII $\alpha$-positive forebrain excitatory neurons from P2 to P14 (Pati et al., 2020) resulted in enhanced anxiety-like behaviors and perturbed social behavior. An important experimental counterpart would be to increase inhibition in forebrain pyramidal neurons in these developmental windows and to address the influence on the emergence of mood-related behaviors. Here we provide evidence of the consequences of enhanced hM4Di-mediated DREADD inhibition of forebrain excitatory neurons on the emergence of mood-related behavior and indicate that this perturbation does not appear to influence the development of either anxiety- or despair-like behaviors in both male and female mice. However, we report clear sex differences on specific measures of anxiety- and despair-like behavioral tasks, in agreement with prior studies (Scholl et al., 2019), with enhanced locomotion noted in the OFT in females, accompanied by greater anxiety-like behavior on the OFT, EPM test, and LD box test in the female cohorts. We also find that, despite a clear decline in the percentage of time spent in open arms of the EPM in the vehicle and PNCNO female groups, the number of entries to the open arms were significantly higher, as previously reported (Knight et al., 2021). Our focus was to address whether chronic hM4Di-DREADDmediated inhibition of CaMKII $\alpha$-positive forebrain excitatory neurons during the early postnatal window alters anxiety-like behavior, and our studies indicate no significant effects of PNCNO administration despite the baseline sex differences noted in anxiety- and despair-like behavior uncovered in male and female cohorts. A prior study using viral-based targeting strategies to evoke hM4Dimediated DREADD inhibition of neurons within the medial prefrontal cortex (PFC) during the postnatal developmental window indicated that this perturbation enhanced anxiety- and despair-like behavior in adulthood, whereas hM3Dq-mediated DREADD activation overlapping with the stress of MS ameliorated the behavioral consequences of early stress in male mice (Teissier et al., 2020). Further, a recent report also examined the influence of chemogenetic inhibition of PFC neurons, which are transiently positive for the serotonin transporter in postnatal life, and showed that the enhanced anxiodepressive behaviors noted in adult animals with a history of postnatal SSRI exposure was exacerbated on hM4Di-DREADDmediated inhibition of this subclass of PFC neurons in adulthood in both male and female mice. In contrast, 
hM3Dq-DREADD-mediated activation of these PFC neurons in adulthood ameliorated the postnatal SSRI-evoked anxiety- and despair-like behaviors (Soiza-Reilly et al., 2019). Studies conducted in mice targeting PFC glutamate projection neurons using the $\mathrm{CaMKII} \alpha$ promoter to drive hM4Di-DREADD virally during postnatal life, followed by an acute treatment with CNO in adulthood, indicated no behavioral changes in the FST, OFT, and novelty-suppressed feeding test baseline, but served to exacerbate the anxiodepressive behavioral phenotypes in mice with a history of postnatal fluoxetine treatment (Soiza-Reilly et al., 2019). It is of importance to note that the promoters used in these studies in specific cases target both excitatory and inhibitory neurons of the PFC or a subclass of raphe-projecting PFC neurons further the use of transgenic mice versus viral-mediated gene delivery, and differences in the developmental epoch targeted and nature of experimental paradigms make it challenging to directly compare our findings with these studies, in particular given that we targeted hM4Di-mediated DREADD expression to all CaMKIl $\alpha$-positive forebrain excitatory neurons and these prior studies assessed effects on a subset of PFC neurons.

While we observed no change in anxiety-like behavior on the OFT, EPM test, and LD avoidance test, we did note that PNCNO-treated CaMKII $\alpha$-tTA::TRE-hM4Di bigenic male mice exhibited a higher basal acoustic startle response, although they showed no change in PPI behavior. An enhanced baseline acoustic startle response has been suggested to be reflective of enhanced anxiety-like behavior (Grillon, 2008); however, we see no indication of perturbation in anxiety on any of the conflictanxiety behavioral tasks. We cannot preclude the possibility of a developmental perturbation of acoustic sensory circuits, given the driver we have used is broad based, and the hM4Di-DREADD would be driven in all forebrain excitatory neurons. One of the caveats of our sensorimotor gating studies is that we have restricted our PNCNO experiments to CaMKII $\alpha$-tTA::TRE-hM4Di bigenic male mice in adulthood, and so we cannot preclude the possibility that there could be effects on sensorimotor gating in female mice subjected to PNCNOmediated hM4Di-DREADD inhibition of CaMKII $\alpha$-positive forebrain excitatory neurons. Collectively, our results suggest that enhancing $G_{i}$ signaling in forebrain excitatory neurons during the postnatal window does not influence the programming of anxiety- and mood-related behaviors in both male and female mice; however, it is vital to keep in mind that this is not the same as driving enhanced $G_{i}$ signaling via a specific GPCR, such as the $5-\mathrm{HT}_{1 \mathrm{~A}}$ receptor, and indeed it is possible that a more targeted approach to selectively enhance $5-\mathrm{HT}_{1 \mathrm{~A}}$ receptor signaling in forebrain excitatory neurons in this developmental window could exert a role in programming changes in emotionality. It would also be of interest to address whether the hM4Di-DREADD-mediated inhibition of forebrain excitatory neurons in this critical temporal window can influence performance on cognitive tasks, which has not been addressed in the present study.
In our study, we have also addressed whether hM4DiDREADD-mediated inhibition of forebrain excitatory neurons in another critical temporal window implicated in shaping mood-related behavioral traits, namely the juvenile window, could impact anxiety- and despair-like behaviors (Brydges et al., 2012, 2014; Hollis et al., 2013; Luo et al., 2014; Suri et al., 2015; Albrecht et al., 2017). Animals subjected to stress during the juvenile window exhibit increased anxiety-like behavior, show enhanced benzodiazepine sensitivity, and can establish a heightened vulnerability to adult-onset stress (Avital and Richter-Levin, 2004). Peripubertal stress also causes alterations in GABAergic neurotransmission (Tzanoulinou et al., 2014), and GAD65 haplodeficiency has been shown to be associated with resilience to juvenile stress-induced increased anxiety-like behavior, possibly because of delayed maturation of inhibitory signaling (Müller et al., 2014). Previous studies have shown that enhanced $G_{q}$ mediated signaling via a chemogenetic approach in the juvenile window does not influence anxiety-, despair-, or schizophrenia-like behavior (Pati et al., 2020). The present work indicated that hM4Di-DREADD inhibition of forebrain excitatory neurons during the juvenile temporal window does not appear to alter anxiety- or despair-like behaviors and does not influence sensorimotor gating in male mice. One of the lacunae of our study is that we restricted all juvenile perturbations to male mice and hence cannot comment on whether hM4Di-DREADD inhibition of forebrain excitatory neurons during the juvenile temporal window modulates anxiodepressive behaviors and sensorimotor gating in female mice.

The profiling of the behavioral consequences of hM4DiDREADD inhibition of forebrain excitatory neurons in postnatal or juvenile life suggests that this perturbation does not alter the emergence of anxiety, despair, and sensorimotor gating behavior on a variety of behavioral tasks in adulthood. This differs quite starkly from our recent study wherein hM3Dq-DREADD-mediated activation of forebrain excitatory neurons in postnatal, but not juvenile or adult, life resulted in persistent increases in anxiety-, despair-, and schizophrenia-like behavior, accompanied by specific molecular, metabolic, and functional changes in the both the neocortex and the hippocampus (Pati et al., 2020). While we do not observe any change in moodrelated behaviors following hM4Di-DREADD inhibition of forebrain excitatory neurons, we cannot preclude the possibility that these animals may exhibit differential responses to a stressor experience in adulthood. Our work motivates future investigation to address in detail how perturbations in GPCR signaling within forebrain circuits during critical developmental time windows may shape vulnerability or resilience to adult-onset stressors.

\section{References}

Albert PR, Le François B, Vahid-Ansari F (2019) Genetic, epigenetic and posttranscriptional mechanisms for treatment of major depression: the 5-HT1A receptor gene as a paradigm. J Psychiatry Neurosci 44:164-176.

Albrecht A, Müller I, Ardi Z, Çalışkan G, Gruber D, Ivens S, Segal M, Behr J, Heinemann U, Stork O, Richter-Levin G (2017) 
Neurobiological consequences of juvenile stress: a GABAergic perspective on risk and resilience. Neurosci Biobehav Rev 74:21-43.

Alexander GM, Rogan SC, Abbas Al, Armbruster BN, Pei Y, Allen JA, Nonneman RJ, Hartmann J, Moy SS, Nicolelis MA, McNamara JO, Roth BL (2009) Remote control of neuronal activity in transgenic mice expressing evolved G protein-coupled receptors. Neuron 63:27-39.

Altieri SC, Yang H, O'Brien HJ, Redwine HM, Senturk D, Hensler JG, Andrews AM (2015) Perinatal vs genetic programming of serotonin states associated with anxiety. Neuropsychopharmacology 40:1456-1470.

Ansorge MS, Zhou M, Lira A, Hen R, Gingrich JA (2004) Early-life blockade of the 5-HT transporter alters emotional behavior in adult mice. Science 306:879-881.

Ansorge MS, Hen R, Gingrich JA (2007) Neurodevelopmental origins of depressive disorders. Curr Opin Pharmacol 7:8-17.

Ansorge MS, Morelli E, Gingrich JA (2008) Inhibition of serotonin but not norepinephrine transport during development produces delayed, persistent perturbations of emotional behaviors in mice. $\mathrm{J}$ Neurosci 28:199-207.

Anticevic A, Lisman J (2017) How can global alteration of excitation/ inhibition balance lead to the local dysfunctions that underlie schizophrenia? Biol Psychiatry 81:818-820.

Armbruster D, Mueller A, Strobel A, Lesch KP, Brocke B, Kirschbaum C (2011) Predicting cortisol stress responses in older individuals: influence of serotonin receptor $1 \mathrm{~A}$ gene (HTR1A) and stressful life events. Horm Behav 60:105-111.

Avital A, Richter-Levin G (2004) Exposure to juvenile stress exacerbates the behavioural consequences of exposure to stress in the adult rat. Int J Neuropsychopharmacol 8:163-173.

Bagot RC, van Hasselt FN, Champagne DL, Meaney MJ, Krugers HJ, Joëls M (2009) Maternal care determines rapid effects of stress mediators on synaptic plasticity in adult rat hippocampal dentate gyrus. Neurobiol Learn Mem 92:292-300.

Bale TL, Baram TZ, Brown AS, Goldstein JM, Insel TR, McCarthy MM, Nemeroff CB, Reyes TM, Simerly RB, Susser ES, Nestler EJ (2010) Early life programming and neurodevelopmental disorders. Biol Psychiatry 68:314-319.

Baram TZ, Yi S, Avishai-Eliner S, Schultz L (1997) Developmental neurobiology of the stress response: multilevel regulation of corticotropin-releasing hormone function. Ann N Y Acad Sci 814:252265.

Benekareddy M, Vadodaria KC, Nair AR, Vaidya VA (2011) Postnatal serotonin type 2 receptor blockade prevents the emergence of anxiety behavior, dysregulated stress-induced immediate early gene responses, and specific transcriptional changes that arise following early life stress. Biol Psychiatry 70:1024-1032.

Bredy TW, Grant RJ, Champagne DL, Meaney MJ (2003) Maternal care influences neuronal survival in the hippocampus of the rat. Eur J Neurosci 18:2903-2909.

Brydges NM, Hall L, Nicolson R, Holmes MC, Hall J (2012) The effects of juvenile stress on anxiety, cognitive bias and decision making in adulthood: a rat model. PLoS One 7:e48143.

Brydges NM, Jin R, Seckl J, Holmes MC, Drake AJ, Hall J (2014) Juvenile stress enhances anxiety and alters corticosteroid receptor expression in adulthood. Brain Behav 4:4-13.

Champagne DL, Bagot RC, van Hasselt F, Ramakers G, Meaney MJ, de Kloet ER, Joëls M, Krugers H (2008) Maternal care and hippocampal plasticity: evidence for experience-dependent structural plasticity, altered synaptic functioning, and differential responsiveness to glucocorticoids and stress. J Neurosci 28:6037-6045.

Chen Y, Baram TZ (2016) Toward understanding how early-life stress reprograms cognitive and emotional brain networks. Neuropsychopharmacology 41:197-206.

Cymerblit-Sabba A, Lasri T, Gruper M, Aga-Mizrachi S, Zubedat S, Avital A (2013) Prenatal enriched environment improves emotional and attentional reactivity to adulthood stress. Behav Brain Res 241:185-190.
De Melo SR, De David Antoniazzi CT, Hossain S, Kolb B (2018) Neonatal stress has a long-lasting sex-dependent effect on anxiety-like behavior and neuronal morphology in the prefrontal cortex and hippocampus. Dev Neurosci 40:93-103.

Di Segni M, Andolina D, Ventura R (2018) Long-term effects of early environment on the brain: lesson from rodent models. Semin Cell Dev Biol 77:81-92.

Fenton AA (2015) Excitation-inhibition discoordination in rodent models of mental disorders. Biol Psychiatry 77:1079-1088.

Francis DD, Diorio J, Plotsky PM, Meaney MJ (2002) Environmental enrichment reverses the effects of maternal separation on stress reactivity. J Neurosci 22:7840-7843.

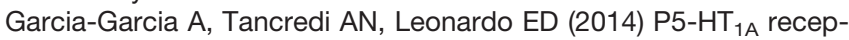
tors in mood and anxiety: recent insights into autoreceptor versus heteroreceptor function. Psychopharmacology (Berl) 231:623636.

Gordon JA, Hen R (2004) The serotonergic system and anxiety. Neuro Mol Med 5:27-40.

Grillon C (2008) Models and mechanisms of anxiety: evidence from startle studies. Psychopharmacology (Berl) 199:421-437.

Gross C, Hen R (2004) The developmental origins of anxiety. Nat Rev Neurosci 5:545-552.

Gross C, Santarelli L, Brunner D, Zhuang X, Hen R (2000) Altered fear circuits in 5-HT(1A) receptor KO mice. Biol Psychiatry 48:11571163.

Gross C, Zhuang X, Stark K, Ramboz S, Oosting R, Kirby L, Santarelli L, Beck S, Hen R (2002) Serotonin1A receptor acts during development to establish normal anxiety-like behaviour in the adult. Nature 416:396-400.

Hensch TK (2005) Critical period plasticity in local cortical circuits. Nat Rev Neurosci 6:877-888.

Hollis F, Isgor C, Kabbaj M (2013) The consequences of adolescent chronic unpredictable stress exposure on brain and behavior. Neuroscience 249:232-241.

Ishikawa C, Shiga T (2017) The postnatal 5-HT1A receptor regulates adult anxiety and depression differently via multiple molecules. Prog Neuropsychopharmacol Biol Psychiatry 78:66-74.

Kalinichev M, Easterling KW, Plotsky PM, Holtzman SG (2002) Longlasting changes in stress-induced corticosterone response and anxiety-like behaviors as a consequence of neonatal maternal separation in Long-Evans rats. Pharmacol Biochem Behav 73:131-140.

Kempermann G, Kuhn HG, Gage FH (1997) More hippocampal neurons in adult mice living in an enriched environment. Nature 386:493-495.

Knight $\mathrm{P}$, Chellian R, Wilson R, Behnood-Rod A, Panunzio S, Bruijnzeel AW (2021) Sex differences in the elevated plus-maze test and large open field test in adult Wistar rats. Pharmacol Biochem Behav 204:173168.

Ko MC, Lee LJH, Li Y, Lee LJ (2014) Long-term consequences of neonatal fluoxetine exposure in adult rats. Dev Neurobiol 74:10381051.

Kusserow H, Davies B, Hörtnagl H, Voigt I, Stroh T, Bert B, Deng DR, Fink H, Veh RW, Theuring F (2004) Reduced anxiety-related behaviour in transgenic mice overexpressing serotonin $1 \mathrm{~A}$ receptors. Brain Res Mol Brain Res 129:104-116.

Lambe EK, Fillman SG, Webster MJ, Weickert CS (2011) Serotonin receptor expression in human prefrontal cortex: balancing excitation and inhibition across postnatal development. PLoS One 6: e22799.

Luo XM, Yuan SN, Guan XT, Xie X, Shao F, Wang WW (2014) Juvenile stress affects anxiety-like behavior and limbic monoamines in adult rats. Physiol Behav 135:7-16.

Marín O (2016) Developmental timing and critical windows for the treatment of psychiatric disorders. Nat Med 22:1229-1238.

Mayford M, Bach ME, Huang YY, Wang L, Hawkins RD, Kandel ER (1996) Control of memory formation through regulated expression of a CaMKII transgene. Science 274:1678-1683.

Medendorp WE, Bjorefeldt A, Crespo EL, Prakash M, Pal A, Waddell ML, Moore Cl, Hochgeschwender U (2021) Selective postnatal 
excitation of neocortical pyramidal neurons results in distinctive behavioral and circuit deficits in adulthood. iScience 24:102157.

Mineur YS, Einstein EB, Bentham MP, Wigestrand MB, Blakeman S, Newbold SA, Picciotto MR (2015) Expression of the 5-HT1A serotonin receptor in the hippocampus is required for social stress resilience and the antidepressant-like effects induced by the nicotinic partial agonist cytisine. Neuropsychopharmacol 40:938946.

Müller I, Obata K, Richter-Levin G, Stork O (2014) GAD65 haplodeficiency conveys resilience in animal models of stress-induced psychopathology. Front Behav Neurosci 8:265.

Nelson SB, Valakh V (2015) Excitatory/Inhibitory balance and circuit homeostasis in autism spectrum disorders. Neuron 87:684-698.

Pati S, Saba K, Salvi S, Tiwari P, Chaudhari P, Verma V, Mukhopadhyay S, Kapri D, Suryavanshi S, Clement J, Patel A, Vaidya V (2020) Chronic chemogenetic activation of forebrain excitatory neurons in postnatal life evokes long-lasting changes in mood-related behavior. Elife 9:e56171.

Ramboz S, Oosting R, Amara DA, Kung HF, Blier P, Mendelsohn M, Mann JJ, Brunner D, Hen R (1998) Serotonin receptor 1A knockout: an animal model of anxiety-related disorder. Proc Natl Acad Sci U S A 95:14476-14481.

Raper J, Murphy L, Richardson R, Romm Z, Kovacs-Balint Z, Payne C, Galvan A (2019) Chemogenetic inhibition of the amygdala modulates emotional behavior expression in infant rhesus monkeys. eNeuro 6:ENEURO.0360-19.2019.

Ravenelle R, Santolucito HB, Byrnes EM, Byrnes JJ, Donaldson ST (2014) Housing environment modulates physiological and behavioral responses to anxiogenic stimuli in trait anxiety male rats. Neuroscience 270:76-87.

Rebello TJ, Yu Q, Goodfellow NM, Caffrey Cagliostro MK, Teissier A, Morelli E, Demireva EY, Chemiakine A, Rosoklija GB, Dwork AJ, Lambe EK, Gingrich JA, Ansorge MS (2014) Postnatal day 2 to 11 constitutes a 5-HT-sensitive period impacting adult mPFC function. J Neurosci 34:12379-12393.

Richardson-Jones JW, Craige CP, Guiard BP, Stephen A, Metzger KL, Kung HF, Gardier AM, Dranovsky A, David DJ, Beck SG, Hen R, Leonardo ED (2010) 5-HT1A autoreceptor levels determine vulnerability to stress and response to antidepressants. Neuron 65:40-52.

Richardson-Jones JW, Craige CP, Nguyen TH, Kung HF, Gardier AM, Dranovsky A, David DJ, Guiard BP, Beck SG, Hen R, Leonardo ED (2011) Serotonin-1A autoreceptors are necessary and sufficient for the normal formation of circuits underlying innate anxiety. J Neurosci 31:6008-6018.

Roth BL (2016) DREADDs for neuroscientists. Neuron 89:683-694.

Salvi SS, Pati S, Chaudhari PR, Tiwari P, Banerjee T, Vaidya VA (2019) Acute chemogenetic activation of CamKII $\alpha$-positive forebrain excitatory neurons regulates anxiety-like behaviour in mice. Front Behav Neurosci 13:249.

Sarkar A, Chachra P, Vaidya VA (2014) Postnatal fluoxetine-evoked anxiety is prevented by concomitant $5-\mathrm{HT} 2 \mathrm{~A} / \mathrm{C}$ receptor blockade and mimicked by postnatal $5-\mathrm{HT} 2 \mathrm{~A} / \mathrm{C}$ receptor stimulation. Biol Psychiatry 76:858-868.

Savitz J, Lucki I, Drevets WC (2009) 5-HT1A receptor function in major depressive disorder. Prog Neurobiol 21:379-384.

Scholl JL, Afzal A, Fox LC, Watt MJ, Forster GL (2019) Sex differences in anxiety-like behavior in rats. Physiol Behav 211:112670112678.

Sohal VS, Rubenstein JLR (2019) Excitation-inhibition balance as a framework for investigating mechanisms in neuropsychiatric disorders. Mol Psychiatry 24:1248-1257.

Soiza-Reilly M, Meye FJ, Olusakin J, Telley L, Petit E, Chen X, Mameli M, Jabaudon D, Sze J-Y, Gaspar P (2019) SSRIs target prefrontal to raphe circuits during development modulating synaptic connectivity and emotional behavior. Mol Psychiatry 24:726745.

Sparling JE, Baker SL, Bielajew C (2018) Effects of combined preand post-natal enrichment on anxiety-like, social, and cognitive behaviours in juvenile and adult rat offspring. Behav Brain Res 353:40-50.

Sumner BEH, D'Eath RB, Farnworth MJ, Robson S, Russell JA, Lawrence $A B$, Jarvis $S$ (2008) Early weaning results in less active behaviour, accompanied by lower 5-HT1A and higher 5-HT2A receptor mRNA expression in specific brain regions of female pigs. Psychoneuroendocrinology 33:1077-1092.

Suri D, Teixeira CM, Cagliostro MKC, Mahadevia D, Ansorge MS (2015) Monoamine-sensitive developmental periods impacting adult emotional and cognitive behaviors. Neuropsychopharmacol 40:88-112.

Targum SD, Nemeroff CB (2019) The effect of early life stress on adult psychiatric disorders. Innov Clin Neurosci 16:35-37.

Tatti R, Haley MS, Swanson OK, Tselha T, Maffei A (2017) Neurophysiology and regulation of the balance between excitation and inhibition in neocortical circuits. Biol Psychiatry 81:821-831.

Teissier A, Chemiakine A, Inbar B, Bagchi S, Ray RS, Palmiter RD, Dymecki SM, Moore H, Ansorge MS (2015) Activity of raphé serotonergic neurons controls emotional behaviors. Cell Rep 13:19651976.

Teissier A, Le Magueresse C, Olusakin J, A, da Costa BLS, De Stasi AM, Bacci A, Imamura Kawasawa Y, Vaidya VA, Gaspar P (2020) Early-life stress impairs postnatal oligodendrogenesis and adult emotional behaviour through activity-dependent mechanisms. Mol Psychiatry 25:1159-1174.

Tiwari P, Fanibunda SE, Kapri D, Vasaya S, Pati S, Vaidya VA (2021) GPCR signaling: role in mediating the effects of early adversity in psychiatric disorders. FEBS J 288:2602-2621.

Tzanoulinou S, García-Mompó C, Castillo-Gómez E, Veenit V, Nacher J, Sandi C (2014) Long-term behavioral programming induced by peripuberty stress in rats is accompanied by GABAergic-related alterations in the amygdala. PLoS One 9: e94666.

Vetere G, Kenney JW, Tran LM, Xia F, Steadman PE, Parkinson J, Josselyn SA, Frankland PW (2017) Chemogenetic interrogation of a brain-wide fear memory network in mice. Neuron 94:363-374. e4.

Vinkers $\mathrm{CH}$, Oosting RS, van Bogaert MJV, Olivier B, Groenink L (2010) Early-life blockade of 5- $\mathrm{HT}_{1 \mathrm{~A}}$ receptors alters adult anxiety behavior and benzodiazepine sensitivity. Biol Psychiatry 67:309316.

Wang D, Levine JLS, Avila-Quintero V, Bloch M, Kaffman A (2020) Systematic review and meta-analysis: effects of maternal separation on anxiety-like behavior in rodents. Transl Psychiatry 10:174.

Wang X, Zhang C, Szábo G, Sun Q-Q (2013) Distribution of CaMKIl $\alpha$ expression in the brain in vivo, studied by CaMKII $\alpha$-GFP mice. Brain Res 1518:9-25.

Weisstaub NV, Zhou M, Lira A, Lambe E, González-Maeso J, Hornung J-P, Sibille E, Underwood M, Itohara S, Dauer WT, Ansorge MS, Morelli E, Mann JJ, Toth M, Aghajanian G, Sealfon SC, Hen R, Gingrich JA (2006) Cortical 5-HT2A receptor signalling modulates anxiety-like behaviors in mice. Science 313:536-541.

Yizhar O, Fenno LE, Prigge M, Schneider F, Davidson TJ, O'Shea DJ, Sohal VS, Goshen I, Finkelstein J, Paz JT, Stehfest K, Fudim R, Ramakrishnan C, Huguenard JR, Hegemann P, Deisseroth $\mathrm{K}$ (2011) Neocortical excitation/inhibition balance in information processing and social dysfunction. Nature 477:171-178. 